\title{
Exploring the Potential for Electric Retrofit Regulations and an Accreditation Scheme for the UK
}

\author{
Robbie Watts, Aritra Ghosh * (D) and Justin Hinshelwood \\ College of Engineering, Mathematics and Physical Sciences, Renewable Energy, University of Exeter, \\ Exeter EX4 4PY, UK; rw536@exeter.ac.uk (R.W.); j.hinshelwood@exeter.ac.uk (J.H.) \\ * Correspondence: a.ghosh@exeter.ac.uk
}

Citation: Watts, R.; Ghosh, A.; Hinshelwood, J. Exploring the Potential for Electric Retrofit Regulations and an Accreditation Scheme for the UK. Electronics 2021 10, 3110. https://doi.org/10.3390/ electronics10243110

Academic Editors: Zita Vale, Mattia Ricco and John Ball

Received: 11 November 2021 Accepted: 8 December 2021 Published: 14 December 2021

Publisher's Note: MDPI stays neutral with regard to jurisdictional claims in published maps and institutional affiliations.

Copyright: (c) 2021 by the authors. Licensee MDPI, Basel, Switzerland. This article is an open access article distributed under the terms and conditions of the Creative Commons Attribution (CC BY) license (https:// creativecommons.org/licenses/by/ $4.0 /)$.

\begin{abstract}
Electric vehicles have zero tailpipe emissions and can reduce greenhouse gas emissions by up to $90 \%$ compared to internal combustion engine (ICE) vehicles. Electric retrofits involve converting an ICE vehicle to an electric drivetrain, aiding the transition to zero emission vehicles by adapting current vehicles and, thus, reducing the transport sector emissions. Other benefits include charge exemptions in major cities, reduced driving costs, and lower maintenance. The UK has a considerable retrofit market, with a large price range of services offered. There is a varying level of practice undertaken and current regulations may not adequately cover these retrofits. Industrial engagement has highlighted the varying levels and common themes of practice, such as restoration work, computer-aided design, and finite element analysis. Converting the registered fuel type of a vehicle to electricity, post-retrofit, appears to be a limited process, with few steps. Therefore, a regulatory framework, such as an accreditation scheme, could be introduced to ensure high levels of safety and good practice. Future work suggestions include further meetings with the DVLA and DVSA, and meeting the Motor Insurers' Bureau.
\end{abstract}

Keywords: electric vehicle; greenhouse gas emissions; retrofit; UK; battery

\section{Introduction}

Globally, climate change has been highlighted as a paramount issue, with atmospheric $\mathrm{CO}_{2}$ concentrations in 2019 reported to have been greater than at any point within the last 2 million years and the fastest 50-year increase in global surface temperature in 2020 for at least 2000 years [1]. The Intergovernmental Panel on Climate Change (IPCC) stated in their sixth assessment that it is "unequivocal that human influence has warmed the atmosphere, ocean, and land", highlighting that many of these changes are caused by human activity [1,2]. In 2020, the transport sector accounted for approximately $24 \%$ of global direct $\mathrm{CO}_{2}$ emissions caused by fuel combustion, with road vehicles accounting for almost $75 \%$ of those emissions [3], portraying the considerable climate effect created by the sector.

Electric vehicles (EVs) have the potential to address the emissions issue, as they have zero tailpipe emissions and hence can reduce the greenhouse gas (GHG) emissions produced by the transport sector [4]. Even considering emissions from electricity generation, a study states that EVs have the potential to reduce GHG emissions by 30-80\% compared to gasoline internal combustion engine (ICE) vehicles [5], whilst another study highlights the potential GHG emission saving to be about $90 \%$ [6], which would provide a vast reduction in overall emissions if there was a large uptake and transition to EVs. It is more beneficial to utilise electricity generated by solar, wind, biomass, and nuclear energy, rather than fossil fuels, to ensure that maximum emission savings can be made, accounting for indirect source emissions, in addition to the direct emissions of vehicles [7].

Furthermore, utilising battery electric vehicles (BEVs) has the potential to mitigate global GHG emissions by 40-215 Mt CO $2 \mathrm{e}$ and 340-1380 $\mathrm{Mt} \mathrm{CO}_{2} \mathrm{e}$ in 2030 and 2050, respectively [8], highlighting the significant ability of the sector to counteract the current climate 
change effects. In addition to the GHG emission savings, EVs have many other benefits, such as being more energy efficient with an EV motor [9], converting approximately $60 \%$ of electrical energy from the grid to power at the wheels, in comparison to as little as $20 \%$ of energy in the fuel of an internal combustion engine (ICE) vehicle being converted to power at the wheels [8]. Furthermore, in comparison to ICE vehicles, there is less maintenance required, smooth operation, and more progressive acceleration [10].

The UK government established legally binding targets in 2019 to "end its contribution to global warming by 2050", by reaching a net-zero level of all GHG emissions by 2050, compared to 1990 levels [11]. This helps to address the growing issue of climate change, with reports stating that current rates of pollution could lead to irreversible changes to planet earth by 2030 [12], with the potential for a temperature increase of between $1.4^{\circ} \mathrm{C}$ and $4{ }^{\circ} \mathrm{C}$ by 2100 , above preindustrial temperatures, for the most and least ambitious pathways to reduce emissions, respectively [13].

Despite the commitments made by the UK, and, more globally, made in the Paris Agreement, there appears to be limited focus on producing suitable policy to ensure that a large uptake of EVs will be made by consumers [14]. Policy incentives have been utilised by some governments in an attempt to increase the uptake in EVs, however the willingness to transition has remained low in many areas, with a market share for EVs of less than $5 \%$ in several countries [15], whilst Norway has led globally [16] with a share of $75 \%$ in 2020 and Iceland and Sweden reached shares of over $50 \%$ and $30 \%$, respectively [17].

Switching entire fleets of ICE vehicles to new BEVs, would, however, require lots of manufacturing and require many current vehicles to be scrapped, which, therefore, presents its own environmental issues, due to the associated emissions [18]. Retrofitting current ICE vehicles to be electrically powered could, thus, act as a solution to this. A previous study regarding electric retrofits investigated the potential of the conversion process in Germany, by exploring the views of potential customers and industry leaders, as well as highlighting possible business models [19]. The findings highlight that the most common answer by potential customers when asked whether they would make use of car electrification services, is 'probably' [19], portraying an example of a positive public perception regarding the process. In regard to business models, a focus on popular vehicle models of passenger cars below 3.5 tonnes was suggested, with approval and certification of the conversion being completed by the TÜV, also known as the Technical Inspection Association [19]. However, further work is suggested to develop these models, in addition to research regarding major issues, such as electricity supply and battery disposal processes [19].

Electric retrofits in the UK could, therefore, act as an aid towards this net-zero target, by providing an alternative option to new BEVs in the transition to zero emission vehicles, potentially increasing the overall uptake and, thus, speed of adoption [20]. Thus, this helps to address a major global issue of climate change, a largely motivating factor of the paper. There currently appears to be limited literature regarding this topic specifically in the UK and, therefore, this paper aims to investigate the potential requirement for regulations of electric retrofits in the UK, which would ensure that safe, adequate conversions are being completed. The research aims to assess the UK electric retrofit market for road vehicles, as well as to understand the conversion process and any safety standards met. The paper also aims to understand the administrative process of changing the registered fuel type to electricity. It relates to the growing industry of EVs, which encompasses electronic design and manufacturing for components required. Challenges for the paper include the lack of clarity regarding current processes and retrofit companies being unlikely to highlight areas of bad practice, therefore requiring appropriate assessments to be undertaken to explore all aspects. Alongside the authors, industrial partners helped to facilitate the paper by providing necessary contacts and organising the industrial visits carried out.

The structure of the work is as follows: Section 2 highlights the overall methodology of the work; Section 3 describes the EV scenario in the UK including the development of EVs, batteries, and charging points as well as safety issues, regulations, and financial schemes. Section 4 illustrates the electric retrofit by exploring the technical procedure and current 
practices, as well as the available benefits. Accreditation schemes for EV technologies are shown, highlighting previous requirements for regulations. Additionally, safety aspects are discussed to highlight the dangers of the technology and, thus, the need for regulations and good practice, whether for new EVs or retrofits. Original equipment manufacturer (OEM) standards, highlighting an exceptional level of practice, are detailed, providing core aspects to be considered for retrofits. EV financial schemes are highlighted, showing different incentives available. Finally, the details for changing the registered fuel type of a vehicle are explored.

\section{Materials and Methods}

Literature relating to road transport emissions, EVs, and their associated infrastructure, electric retrofit conversions, current regulations, and standards, as well as EV financial schemes, was analysed and reviewed. Google scholar was predominately utilised to source these reports and journals, with keywords, such as EVs and electric retrofits, being inputted. UK government documentation was reviewed to understand the processes currently required to convert the registered fuel type of a petrol or diesel vehicle to electric. This documentation was also utilised to review the UK's plans and intentions to limit GHG emissions.

Meetings were held with the Driver and Vehicle Licensing Agency (DVLA) and the Driver and Vehicle Standards Agency (DVSA) to discuss the apparent processes required and the regulations to be met, reviewing the flow diagrams to promote further discussion. To support the limited amount of literature regarding electric retrofits, several site visits to current passenger car and bus retrofit companies were undertaken, to gain an understanding of the conversion processes being used and any safety regulations or standards being met. Due to confidentiality reasons, company names have been omitted, however, all organisations were UK-based to align with the focus of the report. The 'Innovation and Technology in Transport (ITT) Hub' exhibition [21] was attended, to explore the variety of new electric vans, buses, and coaches being produced by different OEMs. The findings obtained from the company and exhibition visits were analysed and discussed to highlight common themes and differences. Recommendations were produced of the regulations to be adhered to in an accreditation scheme for the electric retrofit process. As a result of the research, flow diagrams were produced to portray the apparent processes of converting a fuel type to electric, for cars/vans and buses which are documented in Section 5.

\section{Electric Vehicles Scenario in the UK}

Two key considerations for a transition to EVs in the UK are the emissions and cost differences between ICE vehicles and EVs. In 2019, the transport sector accounted for $27 \%$ of the total GHG emissions produced in the UK, with the main source of these emissions being petrol and diesel vehicles [22]. Within the sector, road transport emitted $91 \%$ of total GHG emissions, equating to 110.7 mega tonnes of carbon dioxide equivalent $\left(\mathrm{MtCO}_{2} \mathrm{e}\right)$ [23]. Figure 1 displays the proportion of road transport emissions that were emitted by each vehicle category, highlighting that the vast number of emissions accounted for by passenger cars is $68 \%$. 


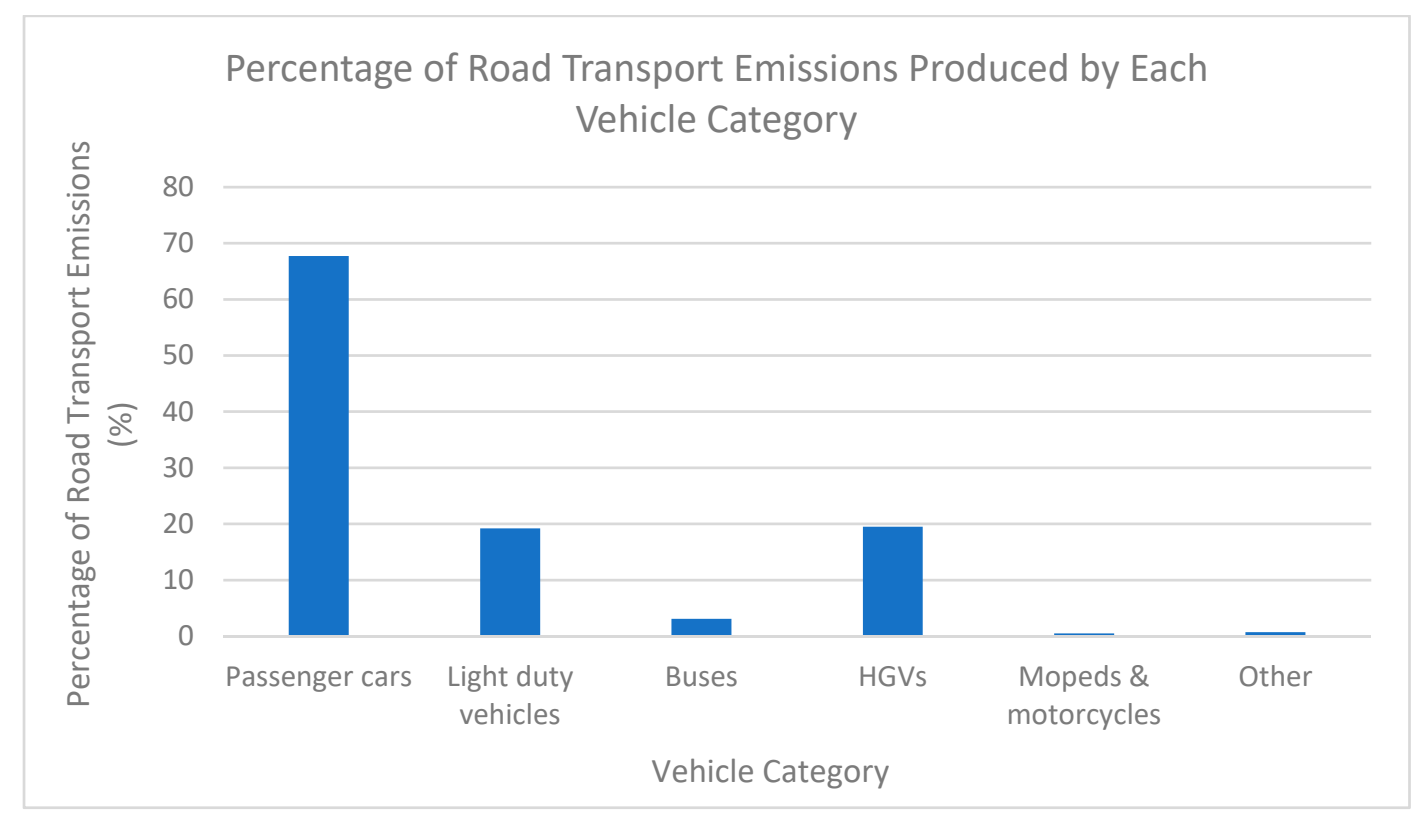

Figure 1. Chart displaying the proportion of road transport emissions for each vehicle category. Source of data: [23].

Passenger cars accounted for 55\% of total transport GHG emissions, equating to $15 \%$ of total GHG emissions produced in the UK in 2019 [23]. Buses account for much fewer emissions than passenger cars- $3 \%$ of road transport, or $2.5 \%$ of total transport, GHG emissions [23] - however, for every fully loaded bus, 75 cars could be removed from the road [24], which highlights the greater effect they could have if there was an increased usage. For example, if electric bus services were more readily available in major cities, they could potentially replace a proportion of car and van traffic.

Although EVs have low operating costs, the life cycle costs (LCC) of EVs are still not competitive with ICE vehicles due to high battery costs. However, the cost of EVs is likely to be affordable after the technological improvement of the batteries [6,10]. A further consideration was the uncertainty in the future costs of petrol, diesel, and electricity [6], which could have a considerable effect on these LCCs. Regarding the initial, upfront costs specifically, a study in the USA in July 2021, highlighted that EVs were still more expensive to produce than ICE vehicles [25], however, lithium-ion battery pack costs had decreased by $85 \%$ between 2010 and 2018 [26]. If these costs continue to decrease, then price parity between EVs and ICE vehicles could be met, however, there appears to be a lot of uncertainty on when this may happen, although, within 10 years is suggested by many estimates [25]. Figure 2 highlights the total cost of ownership of a medium-sized car, bought new in 2021, depending on whether it was a petrol or diesel ICE vehicle, or a BEV [27]. Additionally, the cost of ownership was shown for different stages of ownership, which highlighted the considerably lower cost of a BEV, for the third owner (considered as a cost over seven years), at $£ 15,919$ compared to $£ 21,561$ and $£ 19,398$ for petrol and diesel ICE vehicles, respectively [27]. This highlights the cost benefits of a BEV over time, despite the similar costs near the start of ownership, saving $26 \%$ and $18 \%$ as the third owner, compared to a petrol and diesel ICE vehicle, respectively. The data assumes that the price of energy is equivalent to the UK average residential electricity price $(22 \mathrm{p} / \mathrm{kWh})$ and the fuel duty and VAT, for petrol and diesel, remain constant at 2020 levels [27]. Additionally, annual mileages of $15,000 \mathrm{~km}, 12,000 \mathrm{~km}$, and 10,000 km are applied to the calculations for the first, second, and third owner stages, respectively [28]. 


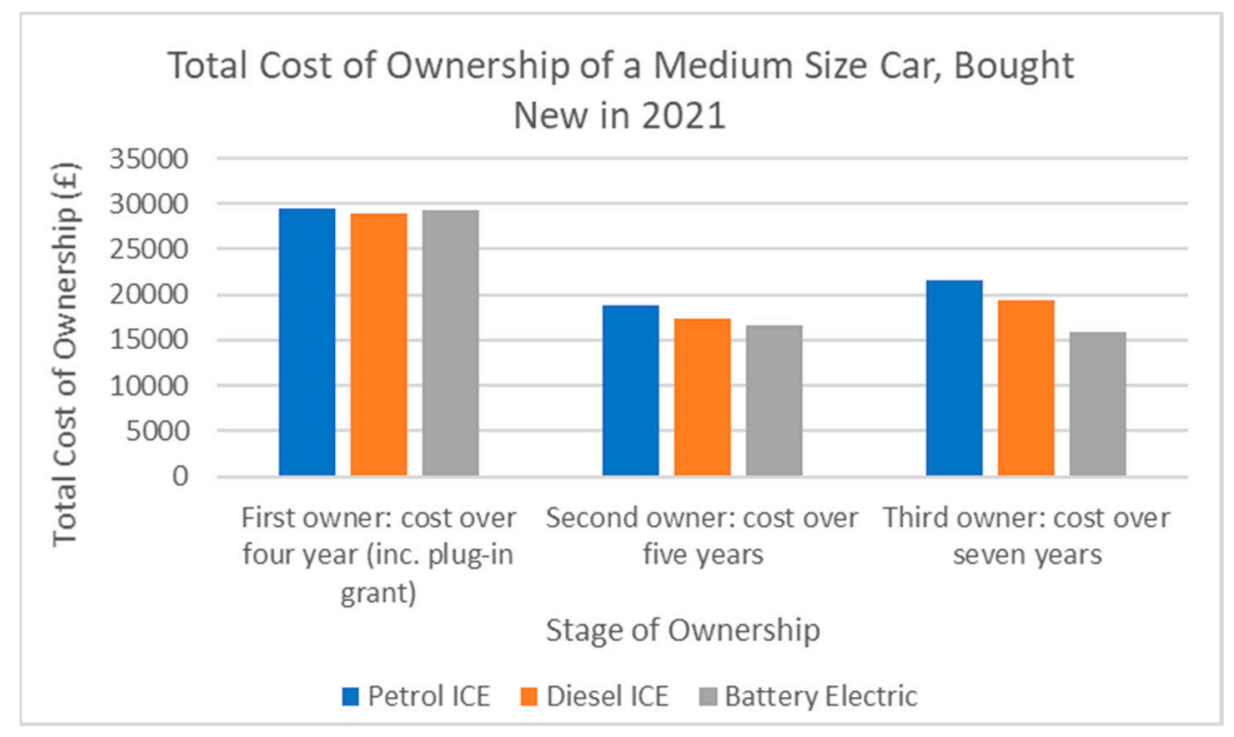

Figure 2. Total cost of ownership comparison for petrol and diesel internal combustion engine (ICE) vehicles and battery electric vehicles (BEVs). Source of data: [27].

\subsection{Development in EV Production}

The rate of EV production portrays an overall situation of EV development in the UK. The predicted growth in the number of BEVs in the UK, up to 2050, is shown in Figure 3, highlighting a vast predicted increase of up to 30 million BEVs in 2050 from less than 1 million in 2020 [5].

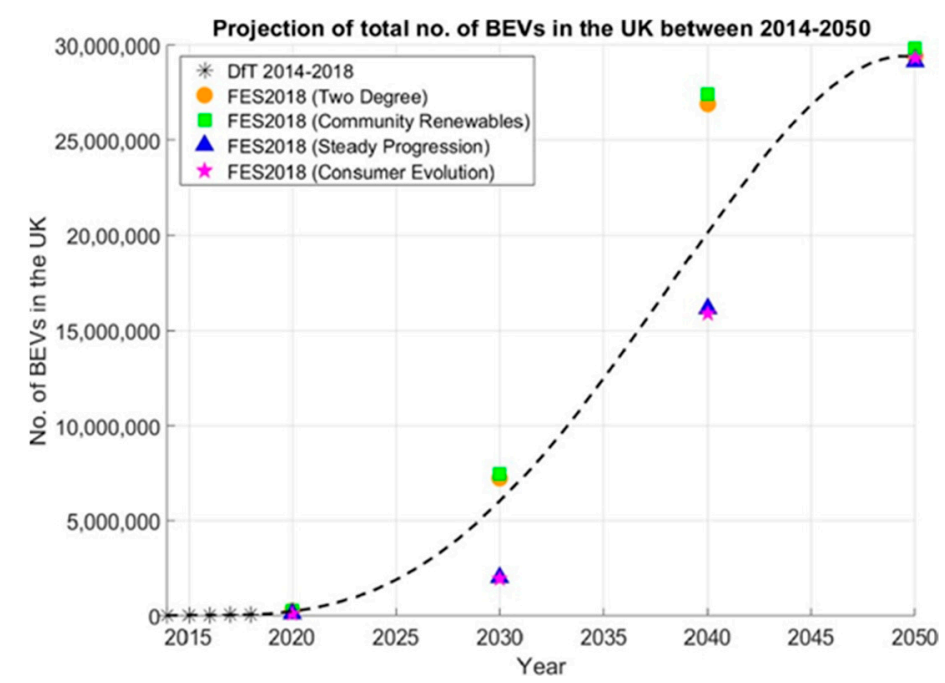

Figure 3. Predicted growth in battery electric vehicles (BEVs in the UK up to 2050 [5].

Globally, the number of EVs has increased greatly over the last decade, with approximately 11.3 million EVs in 2020, compared to 0.3 million in 2012, as shown below in Figure 4 [17]. Despite global car sales dropping by $16 \%$ in 2020, electric car registrations increased by $41 \%$ [17], highlighting the increased uptake of EVs, despite a global pandemic occurring. This growth could continue to increase greatly with the Sustainable Development Scenario-a proposal from the International Energy Agency for future energy-related developments—suggesting a global EV fleet of 230 million vehicles in 2030 [17]. 


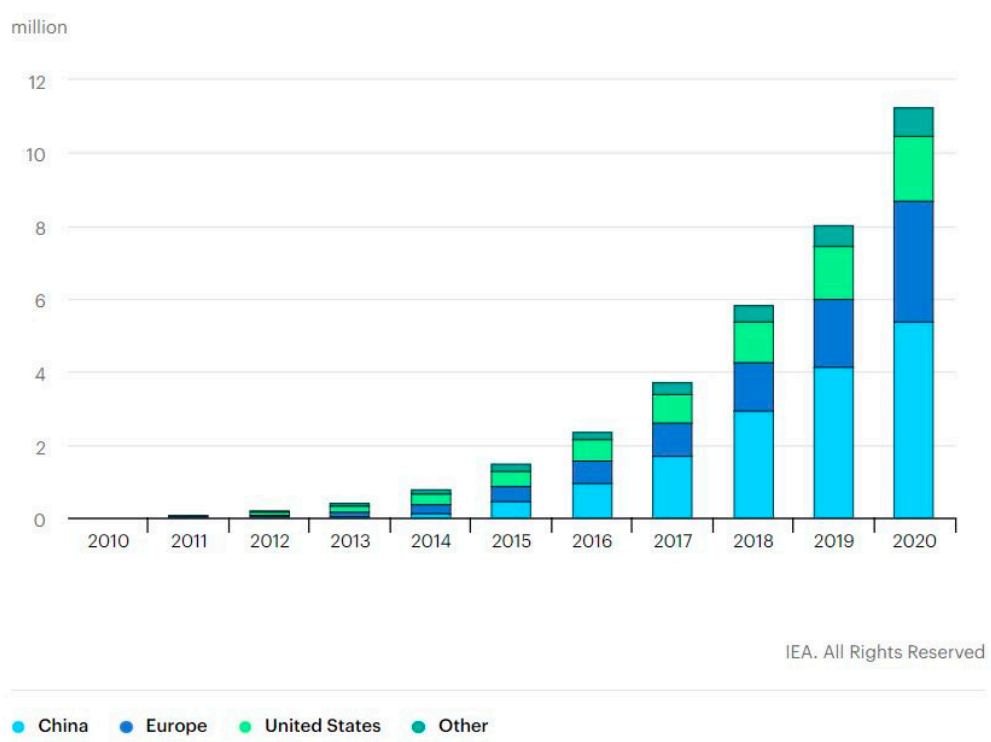

Figure 4. Graph highlighting the growth in the number of EVs globally from 2010 to 2020 [17].

In Great Britain, there were 38.6 million total vehicles licensed at the end of March 2021 [29], with nearly 260,000 BEVs and 280,000 plug-in hybrid vehicles registered in the UK at the end of May 2021 [30]. Although this is still a small proportion of the total number of vehicles, the growth in the registration of EVs is increasing quickly. For example, in the first quarter of 2021, ultra-low emission vehicles-vehicles reported to emit less than $75 \mathrm{~g}$ of $\mathrm{CO}_{2}$ from the tailpipe per kilometre travelled-accounted for $10.4 \%$ of all new vehicle registrations in the UK [29].

\subsection{Battery Development}

Batteries are a major component of an EV, resulting in wide adoption and an expected major increase in battery demand, which will require increased supplies of natural resources and could potentially cause supply-chain issues [31]. Therefore, the development of battery technologies and the increase in battery manufacturing is paramount to the continued production of EVs.

In the UK, Nissan, a Japanese vehicle manufacturer, is currently planning to build a battery 'gigafactory' (a term referring to the unit of measurement representing billions, suggesting mass production), to aid a vast increase in production of EVs, with the capacity to produce batteries for 100,000 vehicles per year [32]. Additionally, Britishvolt has plans to build a battery production plant on the former power station in Blyth, which aims to produce batteries for 300,000 vehicles per year [32]. In Coventry, there are plans to produce a battery gigafactory, as a joint venture by the airport and the city council, provided $£ 2$ billion of investment can be secured [33]. Throughout Europe, there are currently several gigafactories with plans for many more to be developed. In northern Sweden, there is a vast gigafactory currently being produced by Northvolt, which, alongside its base just outside Stockholm, aims to produce 25\% of Europe's electric batteries, initially providing for 300,000 vehicles per year, with the potential to increase its supply to 1 million vehicles per year [34]. Northvolt aim to produce sustainable batteries, by utilising clean, locally sourced renewable energy to power their manufacturing process, creating an $80 \%$ lower carbon footprint compared to batteries made using electricity largely generated by coal-fired power stations [35]. Furthermore, the batteries are expected to be $97 \%$ recyclable, allowing most of the battery cell to be reused to manufacture new ones [35], with plans for an on-site battery recycling plant [34]. In addition, Freyr, a Norwegian energy company, is planning to build a gigafactory in Mo i Rana, Norway, fuelled by wind and hydro energy, whilst Daimler and BMZ have created gigafactories in Germany, and major Asian battery brands have set up gigafactories in Europe-with an LG Chem plant in Poland and Samsung 
SDI and SK Innovation plants in Hungary [34]. In regard to battery requirements, in the USA, for example, there are proposed new rules, starting in 2026, requiring that BEVs "maintain $80 \%$ of their range for 15 years or 150,000 miles", and that there is a "customer readable state of health metric", to allow buyers to simply check the state of health of the battery pack [36]. Additionally, a study suggests how stating the remaining battery life could improve the EVs value, because the driving profile has a large impact on battery life and, therefore, without paperwork to show how the battery has been treated, the value stays below its potential [37]. Moreover, charging and discharging cycles, as well as cell temperature, have an impact on the lifespan of batteries [38].

\subsection{Charging Points}

Charging points are an essential infrastructure requirement for a successful transition to EVs in the UK. In August 2021, according to Zap-map, there were 25,145 public charging devices, with a total of 43,210 connectors, at 15,886 different locations within the UK [39]. This number has risen greatly over the past five years, as shown below in Figure 5, with only 6500 public charging points in the UK in 2016, as well as a more recent increase of $48 \%$ from 2019 to August 2021 (year to date) [39]. In comparison, there were approximately 8400 petrol refuelling stations (operational and under development) in the UK in February 2021 [40], which is far lower than the number of charging points, highlighting the reasonable availability for EV charging in comparison to ICE vehicle refuelling. Each refuelling station does often have several pumps, though, which would be comparable to the number of connectors.

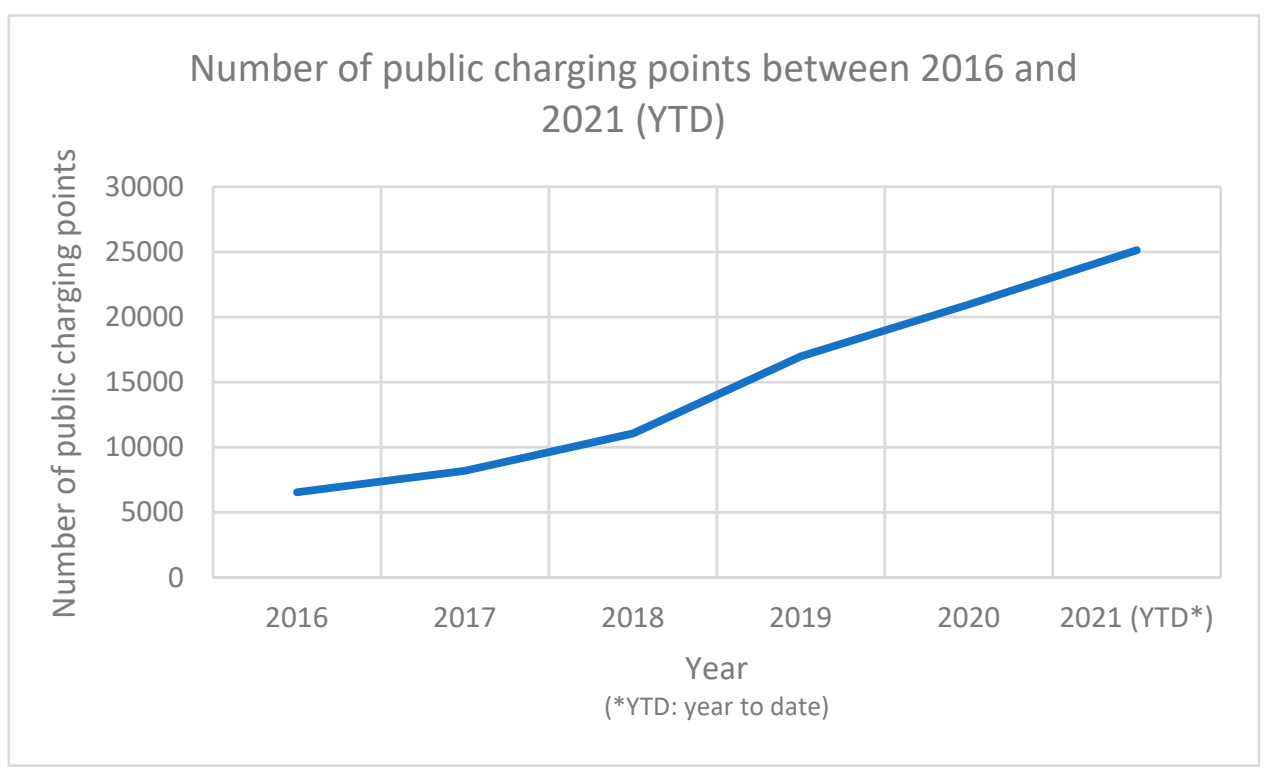

Figure 5. Chart highlighting the growth in public charging points between 2016 and 2021; data shown until the 6 August 2021 [39].

In 2017, a survey by the energy supplier 'OVO energy' highlighted that the number one reason for not buying an EV in the UK was the lack of charging points, with $56 \%$ of participants stating this [41]. Therefore, the vast increase in charging points since then should help to address this public concern. Additionally, following a commitment from Highways England to increase the number of charge points in the UK, there have been 66 rapid charge points installed, which ensures that $97.4 \%$ of the 'Strategic Road Network', comprising of motorways and major A roads in England, will be within 20 miles of a rapid charge point [42]. This infrastructure development also, therefore, helps to address the issue of unevenly distributed charge points, which previously resulted in varying access, considered a "postcode lottery", as highlighted in analysis by HSBC in 2016 [43]. 
With an increased number of electric charging points and increased usage, due to growth in EV sales, the supply of electricity is also required to increase, and to do this sustainably, renewable energy systems are pivotal. It has been estimated that an extra increase in global electricity consumption of $7-10 \%$ by 2040 will be caused by the increase in EVs [44]. Over the past decade, there has been a vast increase in the production of electricity from wind power in the UK, with 75,610 gigawatt-hours produced from offshore and onshore wind in 2020, an increase of 715\% from 2009 to 2020 [45]. Despite this progress, renewable energy generation is required to continue increasing greatly, if electricity is to be supplied to the UK's EV fleet sustainably. Renewable electricity generation in the UK in quarter 1 of 2021 was 34.7 terawatt-hours [46], however, the National Grid estimates that 100 terawatt-hours would be required if all the vehicles on the road in the UK were electric, substantially adding to the current total demand of the country of 300 terawatt-hours [47]. This highlights the major difference in renewable electricity production compared to the general electricity demand currently, and the potential future demand considering widespread EV usage.

\subsection{Safety Challenges for Electric Vehicles}

There are several safety aspects related to EVs and drivetrains, which should also be considered during a retrofit in the UK. A major aspect is electrical hazards, given the large amount of electrical energy that could be stored in batteries, as well as high voltage (HV) cables utilised [48]. Thus, if a fault occurred, this could result in a high-energy release, which could have associated safety implications, and as the battery cannot be switched off, there is an ever-present electrical risk [48]. Other hazards include chemicals, due to their potential release from the battery technology, and collisions, which may cause the battery to be punctured or high-voltage cables to be cut or damaged by the impact, potentially leading to a fire, which is a further risk [48].

Lithium-ion batteries are commonly used for EVs and therefore must be rigorously tested before use to ensure safe operation, as catastrophic failures are possible $[49,50]$. For example, 'thermal runaway' can occur; a process that involves exothermic reactions between the electrodes and electrolyte, at a critical temperature [51]. This can, thus, lead to fire and rupture or explosion of the battery cell, so, therefore, it is important to prevent the spread to other adjacent cells, which would affect the whole battery pack, potentially containing thousands of cells in an EV version [50]. If the onboard battery is involved in a fire, it is extremely difficult to suppress it, as the battery pack is often fairly inaccessible to an external extinguishing device, and reignition may occur without sufficient cooling [52-54]. This is, therefore, worthwhile considering when purchasing and utilising, or designing, battery packs, as it emphasises the necessity for rigorous testing to ensure safety.

Battery management systems are utilised to monitor and optimise battery module performance, and have the ability to disconnect modules from the system during abnormal conditions [55]. The system monitors the state of charge and state of health of the battery, as well as the voltage, temperature, and current to ensure safety from different hazards [55].

To provide protection against direct contact, live parts must be suitably insulated, for example by using wires and enclosures [48]. Often, basic electrical safety protection states that insulation must not be easily removed, only by destruction [56], and must be an appropriate level for the operating voltage of the system [57], to protect electrical professionals in the workplace. It is also necessary to ensure that parts are water-resistant, often installed as sealed units, to ensure that they are not affected by the rain, water on the road, or water during washing.

EVs operate very quietly, particularly at low speeds, and therefore are a potential hazard to other road users [58], especially pedestrians, cyclists, and horse riders, with studies highlighting that the risk of incidents with pedestrians increases by up to $80 \%$, due to EVs or hybrid vehicles [59]. Therefore, products have been developed known as 'Acoustic Vehicle Alerting Systems' to alert road users of a nearby vehicle, by producing a sound whilst the vehicle is travelling between 0 and $20 \mathrm{mph}$ [59]. After this it then cuts 
out as the sound of the vehicle alone is sufficient, exceeding wind and road noise [59]. Furthermore, the United Nations Economic Commission for Europe (UNECE) brought in 'Regulation No. 138', to ensure that new 'quiet road transport' vehicles, such as EVs, are fitted with an acoustic vehicle alerting system, which is tested and approved for each vehicle type [60].

Replacing the ICE and exhaust system with an electric drivetrain will alter the weight distribution of the vehicle, which, for a new EV, will be assessed and analysed in the design and testing stages prior to manufacturing. However, for an electric retrofit, the vehicle has not initially been designed to carry an electric drivetrain, and, therefore, if not considered, it may affect the loads on the chassis, which could cause structural damage at a later date, as well as adversely affect dynamic handling and braking. Additionally, due to the size and mass of the batteries, they can pose a mechanical hazard, so, therefore, it is necessary for them to be fixed in position using appropriate mounts or clamps, preventing potential instability of the vehicle [58].

Safety during maintenance is another aspect to be considered, with suitable protection provided to the user, who may undertake basic maintenance work, whilst vehicle technicians and repair personnel must be adequately trained to ensure complete safety when adjusting and replacing parts [58]. It is necessary to include, within regular maintenance, testing of the insulation resistance of HV parts and testing the leakage current controller function, as well as checking battery condition [58].

These safety hazards, therefore, highlight some of the reasons why electric retrofit conversions must be completed to a suitable standard, primarily to avoid significant failures. Thus, they demonstrate why suitable regulations, and sometimes accreditation schemes, are necessary.

\subsection{Standards and Regulations}

For the production of new EVs by OEMs in the UK, there are many regulations (which mandate following standards) to be adhered to, as well as other non-binding standards to ensure a safe, reliable vehicle is manufactured. Some of the standards specifically relating to EVs, as highlighted by the British Standards Institution, are shown below in Table 1 [61]. It is beneficial to consider these OEM standards for electric retrofit conversions, as the core details are often applicable, as a lot of the same components will be utilised, even though fulfilling the complete standard may be unattainable-for example, due to financial constraints. The regulations mainly relate to the safety of the system and protection against hazards, charging safety and infrastructure, communication and signalling, and safety of battery swapping [61]. They highlight the depth of standards that must be met when manufacturing a new EV and, thus, can provide a guide for electric retrofits, although it may be difficult to reach the same standards as new EVs, logistically and economically. Other common standards include ISO 26262 and ISO 9001 . ISO 26262 refers to the functional safety of road vehicles and, in particular, is for safety-related systems that have an electrical and/or electronic system and are installed in production road vehicles [62]. It highlights how to document the testing process of a component and how to assign an appropriate risk level, using automotive safety integrity levels [63]. ISO 9001 highlights the requirements for a quality management system, based on principles such as a strong customer focus and continual improvement, to ensure customers receive high-quality services and products. Over 1 million companies are certified to ISO 9001 [64]. 
Table 1. Standards provided by the BSI for newly manufactured EVs [61].

\begin{tabular}{|c|c|}
\hline Standard & Information \\
\hline ISO 6469 & $\begin{array}{l}\text { (1) Safety specifications for rechargeable energy storage systems for EVs. (2) Functional and } \\
\text { operational safety means. (3) Specific protection against electrical hazards. }\end{array}$ \\
\hline BS EN IEC 61851-1 & $\begin{array}{l}\text { General requirements for EV conductive charging systems. Covers: Characteristics, specifications } \\
\text { and safety requirements for power supply, and connection between charging equipment and vehicle. }\end{array}$ \\
\hline DD CLC/TS 50457-2 & Communication protocol between an off-board charger and EV in conductive charging situations. \\
\hline IEC TS 61980-2 & $\begin{array}{c}\text { Communication between vehicle + wireless power transfer (WPT) systems connected to supply } \\
\text { network. }\end{array}$ \\
\hline BS EN 62196-2 & $\begin{array}{l}\text { Plugs, socket-outlets, vehicle connectors + vehicle inlets: Dimensional compatibility, } \\
\text { interchangeability requirements for pin + contact-tube accessories. }\end{array}$ \\
\hline BS EN ISO 15118-3 & Physical vehicle-to-grid communication interface, data link requirements, and basic signalling. \\
\hline BS EN ISO 15118-8 & Wireless communication interfaces. \\
\hline IEC TS 62840-1 & Swapping batteries: Discharged one replaced with a fully charged one. \\
\hline BS EN IEC 62840-2 & Specific safety requirements, regarding battery swapping. \\
\hline
\end{tabular}

The IVA process is required if a very small number of vehicles, in certain categoriessuch as passenger cars, buses, coaches, etc.-are being made or imported [65]. There is a basic IVA, involving a visual inspection and tests to ensure the vehicle meet the required standards, and a normal IVA, entailing a more detailed inspection, requiring the vehicle to meet extra standards with documentary evidence supplied [65]. As shown below, in Table 2, there is specific guidance provided for electric and hybrid passenger vehicles (M1), such as having protection on HV cable terminations, clearly marked indelible labels for charging connection points and HV enclosures, orange-coloured HV cables, and earth paths on metal enclosures for electric shock protection [66]. Regulation 100 (R100) is also stated, which highlights standards that must be met for approval. For an electric retrofit, the guidance for a visual inspection is useful to follow to ensure the system is appropriately designed and set up, even if an IVA is not necessarily required. For buses and coaches (M2 and M3), the IVA details are the same, except that the model report must be created by the Technical Application Submission Service [67], instead of by the Customer Service Centre, Ellipse Swansea for passenger vehicles (M1). Otherwise, the requirements for orange cabling and suitable protection of $\mathrm{HV}$ terminations, etc. are still necessary.

Table 2. IVA details for electric and hybrid passenger vehicles (M1) [66].

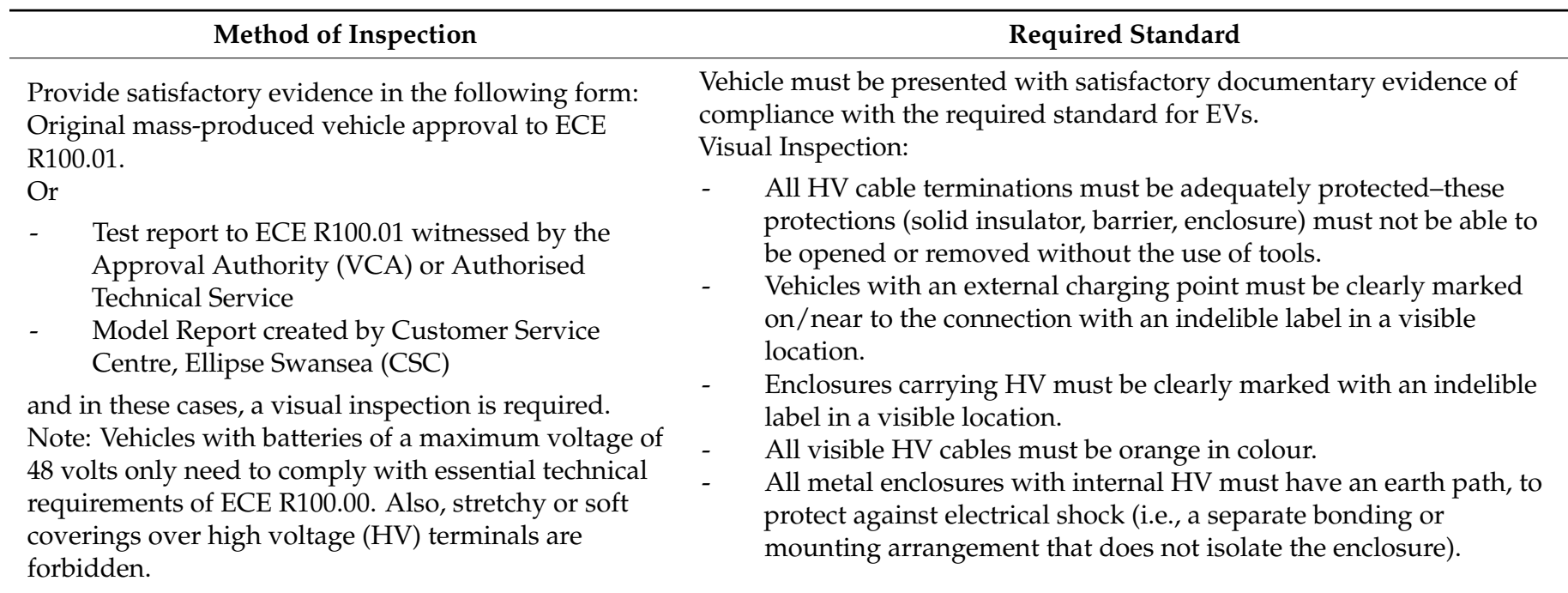


Regulation 100 includes "uniform provisions concerning the approval of vehicles with regard to specific requirements for the electric power train", with part I referring to the electrical safety of the vehicle and part II referring to the safety of the 'Rechargeable Energy Storage System', such as a battery [68]. Within the document, there are many definitions stated, as well as explanations of different tests, with required outcomes and details of the test equipment to be utilised (chassis dynamometer, emission measurement enclosure), in addition to calibration details [68]. There are sections relating to protection against electrical shock and direct contact, stating that "live parts shall be protected against direct contact", and that, without the use of tools, barriers, insulators, and connectors "shall not be able to be opened, separated, disassembled, or removed", unless they meet certain requirements, such as being under the floor or possessing a locking mechanism. Overall, the document provides detailed, informative guidance for EV manufacturers to follow, which is also extremely useful to retrofit conversion companies.

\subsection{EV Financial Schemes}

Firstly, although there are several financial schemes to incentivise EVs, one of the major factors is that EVs are exempt from vehicle excise duty in the UK [69], which can provide owners with considerable savings, given that for ICE vehicles it can reach costs of $£ 2245$ per year [70].

If a vehicle is utilised to commute to work and charged at a charging point at the workplace, the electricity provided by the employer is exempt from being taxed as a benefitin-kind, which is an incentive aimed to persuade employers to provide charging points [71]. Currently, there is an EV 'Homecharge Scheme', which provides a grant of $75 \%$ of the cost of a charge point and its installation, capped at $£ 350$ (including VAT) per installation [72]. The scheme requires the applicant to own, lease, or have ordered, a qualifying vehicle, as well as having dedicated off-street parking at their property [72]. Eligible vehicles are published online, including many new EVs produced by major OEMs, such as the BMW i3 and the Vauxhall Corsa-e [73]. If the scheme was extended to retrofitted vehicles, it could act as an incentive to aid the uptake in retrofits, as more people could afford home charging, and therefore may be more willing to consider converting their vehicle.

Scrappage schemes for vans, minibuses, and heavy vehicles, organised by Transport for London, have been suspended due to "unprecedented demand and limited funds", but they previously offered a grant of $£ 7000$ to $£ 9500$ for vans and minibuses, and $£ 15,000$ for heavy vehicles [74]. The two schemes were available to small businesses, sole traders, and charities, to replace vehicles that do not meet the emissions standards of the ULEZ in London [74]. If there was potential for further funding then this scheme could be adjusted or extended to provide grants for vehicles to be retrofitted from ICEs to electric drivetrains, allowing more consumers to access the conversion, to accelerate the transition to zero emission vehicles. It would be beneficial to have an assessment process that ensures that the vehicle to be converted is of a certain standard, so that the vehicle and its components will function safely for several years, and the conversion would be worthwhile.

In the UK, there is a government 'plug-in' grant of up to $£ 2500$ for the purchase of electric cars, which has been recently reduced from $£ 3000$ [75], and larger grants for bigger vehicles, such as up to $£ 6000$ for large vans and up to $£ 16,000$ for trucks [76]. In France, there is an incentive scheme which provided a subsidy of $€ 7000$ to the purchase of a new electric car in 2020, with a planned update to provide $€ 6000$ in 2021, and then to provide $€ 5000$ in 2022 [77]. In Germany, there is a total subsidy of $€ 9000$ available for new electric cars with a net list price of less than $€ 40,000$, with $€ 6000$ being provided by the Government and $€ 3000$ being provided by the manufacturer [78]. Furthermore, a governmental subsidy of $€ 5000$ or $€ 3750$ is available for second-hand electric and rechargeable hybrid vehicles, respectively, provided they have driven fewer than 15,000 kilometres and were registered after 18 May 2016 [79]. These grants and subsidies highlight the intentions within Europe to accelerate the transition to EVs, with a substantial amount of funding provided, so, 
therefore, there could be potential for an electric retrofit subsidy scheme, to create a financial incentive for owners to convert their vehicles to electric.

In England, the Bus Service Operators Grant (BSOG) currently provides grant funding to operators of local bus services, to offset fuel costs. [80]. In addition to this, an extra 6 pence per kilometre is available to some vehicles holding a low carbon emission certificate (awarded to a vehicle with 22 or more seats that can achieve a $30 \%$ reduction in its GHG emissions versus a Euro 3 diesel bus) [80].

However, in some areas it is paid as a fuel duty rebate, and then electric buses are not eligible as they do not utilise a 'fuel' that duty is paid on [81]. This, therefore, leads to scenarios where a fuel-efficient diesel bus is eligible for more funding than a batteryelectric bus, which disincentives bus operators to switch to zero-emission alternatives [82]. The Department for Transport has, however, highlighted this as a "fossil fuel subsidy" and proposed to reform the current funding, to benefit the environment and improve efficiency [24], which, if completed, would be a progressive step towards zero emission bus growth. In Scotland, under the BSOG, low emission vehicle incentive payments were introduced in 2019, with eligibility being based on GHG emissions and the zero-emission capability of a vehicle [83]. This enables low-emission buses (classified as having a 15-35\% GHG saving versus Euro V) to receive 5 pence per kilometre, at the lower end of the scale, and 'effectively zero-emission' buses (classified as having a 36\% + GHG saving versus Euro $\mathrm{V}$ and a $50-\mathrm{km}$ zero emission range) to receive 30 pence per kilometre, at the other end of the scale [83].

These schemes highlight a number of financial incentives and benefits of EVs, demonstrating the economic support for the sector, which covers electric retrofits in some areas, although there is scope for further inclusion of retrofits, to make the market more viable and popular.

\section{Electric Retrofits}

Electric retrofits offer an alternative option to buying a new EV, whilst gaining most benefits of driving one. They are especially relevant as the UK government have announced that the sale of new petrol and diesel cars and vans will end in 2030, and from 2035 all new cars and vans will have zero emissions at the tailpipe, in an effort to deliver the net zero emissions pledge [84]. This, therefore, is encouraging a mass transition from ICE vehicles to BEVs and other emerging alternatives, such as hydrogen fuel cell vehicles. As discussed earlier, the sector accounts for a vast amount of GHG emissions and, as renewable energy accounts for an ever-increasing share of electricity generation, EVs have the potential to considerably reduce this. As shown in Section 3, the number of EVs sold and being driven has increased vastly, despite some downsides to the technology, such as limited ranges and high costs, compared to new ICE vehicles. Purchasing a brand new EV will not be financially viable for a lot of people and, therefore, if retrofit costs were low enough, they could offer an alternative route to a zero-tailpipe emission vehicle, which could also benefit from the financial advantages of driving an EV, such as reduced running costs and charge exemption from low emission zones. OEMs provide new, electric options for many standard vehicles, however, there are several niche markets that they do not cover comprehensively, such as classic cars and emergency service vehicles. Additionally, some used ICE vehicles may still have a high inherent value and, therefore, despite new electric versions being available, it can be more economically viable to retrofit used vehicles, instead of purchasing new ones. Furthermore, providing a conversion option for classic, sentimental, or collectable vehicles, allows owners to keep their vehicles on the road, without being financially penalised, whilst reducing their effect on the climate. Additionally, the retrofit process can often be completed much more quickly than the production of a new EV, thus, offering an alternative solution to help accelerate the transition to zero emission vehicles, converting current vehicles on the road and, therefore, reducing the amount that would need to be scrapped. 
In a report assessing the lifecycle GHG emissions of a retrofitted electric vehicle compared to an ICE vehicle, over a 150,000-kilometre lifespan mileage, the retrofitted vehicle provided a total GHG reduction potential of $2000-\mathrm{kg} \mathrm{CO}_{2}$ equivalent, or $2350-\mathrm{kg}$ $\mathrm{CO}_{2}$ equivalent, for an electric drivetrain produced locally or shipped from overseas, respectively [85]. On a per kilometre basis, this equates to a potential reduction of $22 \%$ in GHG emissions, for the conversion of an ICE vehicle into a BEV [85]. The lower GHG saving for local production is due to the high fossil fuel use in Western Australia (the area of study), despite the added transportation emissions of overseas production [85]. Another similar study, assessing the life cycle impacts of different vehicles, highlighted a reduction of $36 \%$ in climate change impact of a new EV compared to an ICE vehicle, but a further reduction of $16 \%$ in climate change impact for a converted EV [86]. The graph below, in Figure 6, highlights the decreased lifecycle impact, in terms of $\mathrm{CO}_{2}$ emissions, of retrofitted BEVs compared to new BEVs, with $156 \mathrm{~g} \mathrm{CO}_{2}$-equivalent/ $\mathrm{km}$ versus $180 \mathrm{~g}$, respectively [86]. This was further reduced when a renewable electricity mix was utilised instead of a traditional fossil fuel supply, with impact levels of $97 \mathrm{~g}$ for new BEVs and $72 \mathrm{~g}$ for converted BEVs [86]. Given that the retrofitted BEVs have an even lower lifecycle impact than new BEVs, which is lower than ICE vehicles, they could provide a relatively fast, feasible option to aid the transition to zero tailpipe emission vehicles.

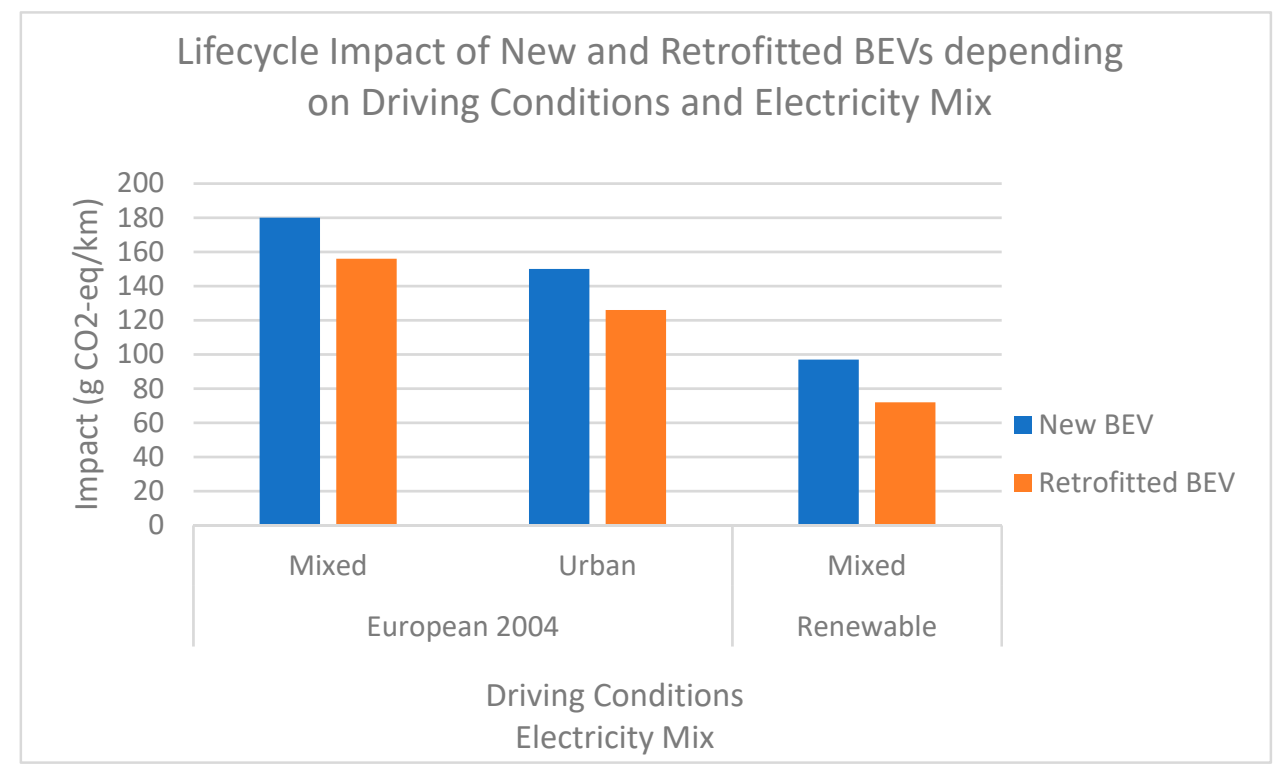

Figure 6. Graph showing the lifecycle impact of new and retrofitted BEVs [86].

For electric retrofits, the current regulations may not be adequate, which could potentially allow unsafe conversions to occur, with unreliable parts, which may produce a serious hazard to vehicle users as well as the general public, either as other road users or as vehicle professionals, such as mechanics/vehicle technicians or Ministry of Transport (MOT) testers.

\subsection{Technical Procedure}

The technical process of an electric retrofit involves removing the previous ICE system, and other related parts, such as the exhaust system and fuel tank, and replacing them with an electric drivetrain, consisting mainly of an electric motor, battery pack, inverter, and power electronics [19]. The electric motor converts electrical energy, from the battery pack, into mechanical energy, to propel the vehicle and cause it to move in the desired direction [87]. Different types of motors can be used, such as brushless synchronous DC, $\mathrm{AC}$ asynchronous induction, or permanent magnet, each with different benefits [87]. The battery is the energy source used to power the propulsion system and different battery chemistries are used depending on the energy requirement and load [87]. The different key 
components included in an EV are shown in the block diagram in Figure 7, highlighting the link between each. The role of the controller is to maintain the vehicle's operating parameters, by regulating the signal, whilst the converter converts the fixed DC voltage from the battery into a variable voltage and a frequency signal, depending on the inputs of the user-for example, from the brake or accelerator pedals [48]. Additionally, there are auxiliaries, such as the lights, a heater, and power steering, which are not used for propulsion, but must be powered [48].

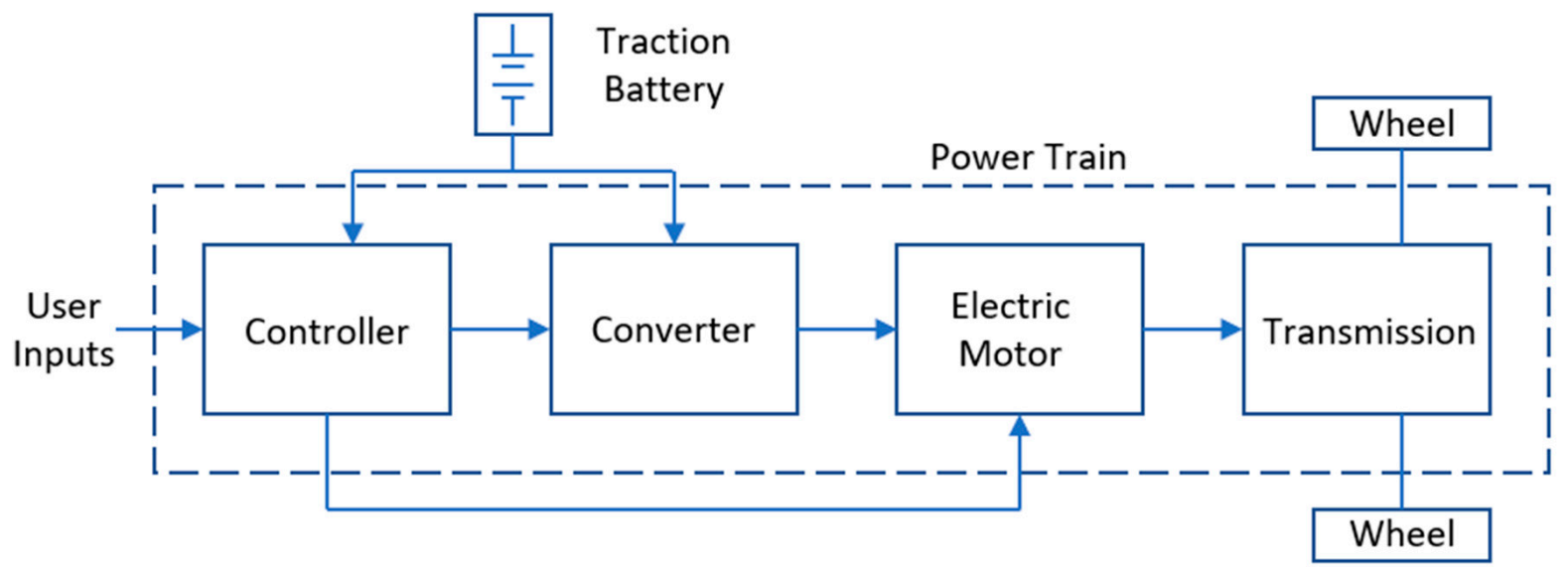

Figure 7. Block diagram highlighting the key components of an electric powertrain, redrawn from [48].

A case study exploring the challenges and solutions of electric retrofits highlighted a time and cost-efficient process to convert an ICE vehicle to an EV, utilising engineering procedures and software to undertake detailed analysis, providing an insight into the extent of work which could be undertaken, and is potentially a necessary requirement, to perform safe, reliable conversion [88]. A high-level overview of the process is shown in Figure 8, highlighting the analysis procedure. Firstly, the computer-aided design (CAD) data for the ICE vehicle and the electric powertrain is obtained, to undertake package analysis and design a layout for the chassis system. ADAMS and CarSim software are utilised to simulate the chassis system and the vehicle dynamics behaviour. Changes in vehicle mass and, thus, centre of gravity are considered in the analysis procedure, as well as ground clearance height [88]. This process, however, is very extensive work, which could be completed by major OEMs, but may be unrealistic for retrofit companies, especially due to the financial implications of lots of modelling software.

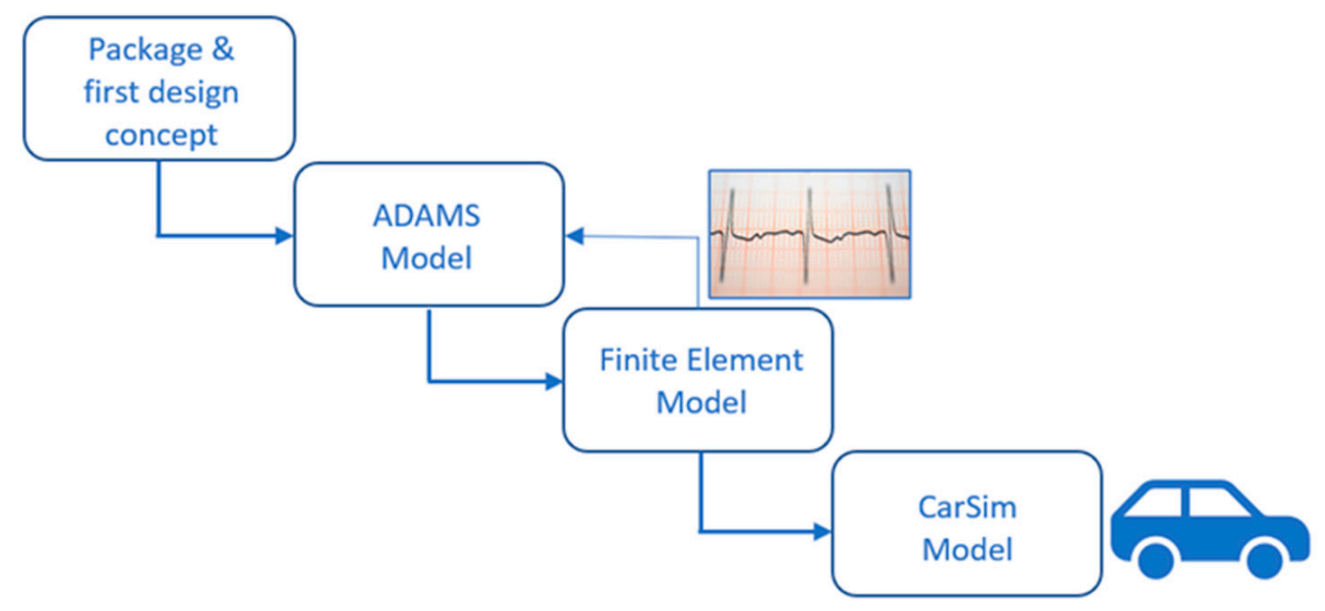

Figure 8. Detailed electric retrofit analysis process as proposed in a study, redrawn from [88]. 
Figure 9 displays the basic layout of an electric drivetrain for an EV, highlighting the electric motor located under the van's bonnet, often known as the 'engine bay' area in ICE vehicles. The motor is able to provide instant torque, as well as being very quiet and requiring lower maintenance than an ICE vehicle [89]. The battery pack is located under the chassis of the vehicle between the front and rear axles, which connect the front and rear wheels, respectively. Fitting it under the chassis, therefore, ensures that the load area in the rear of the vehicle is not decreased. Power electronics are utilised to connect the high-voltage battery to the electric motor and to the onboard electronics, supplying both with energy [89]. Regenerative braking may also be included to recover energy that is commonly lost during braking, by switching the motor to a generator operation and passing the current to the battery, to be stored for future use [89].

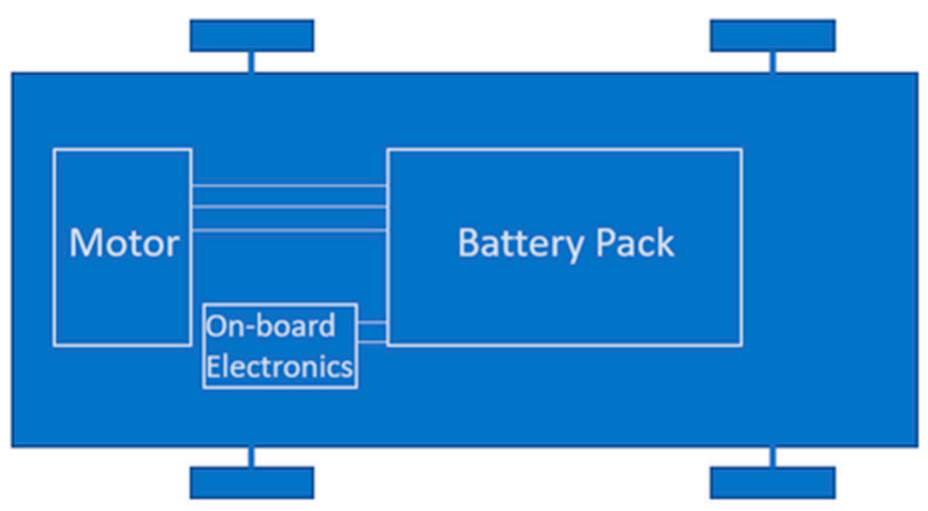

Figure 9. Layout of an electric drivetrain of an EV. Redrawn from [89].

In comparison, for diesel and petrol vehicles, the ICE is located within the engine bay, where the electric motor is situated in an EV, and the exhaust system runs from the bay, along the bottom of the chassis, to the back of the vehicle, as shown in Figure 10. Therefore, to retrofit a current ICE model, the components have to be removed and the available space has to be utilised as appropriately as possible, to fit the electric drivetrain. This will likely require additional mounts and brackets to be added, to hold parts in place, due to the original vehicle design, not considering these new components. Effectively, the electric drivetrain system shown above in Figure 9 must fit into the ICE vehicle layout, shown below in Figure 10. For newer vehicles this may appear simple as the ICE model and EV model may be very similar, despite their fuel type, however completing this process for old classic vehicles that do not have a new electric version already being manufactured, requires new designs and solutions to be created.

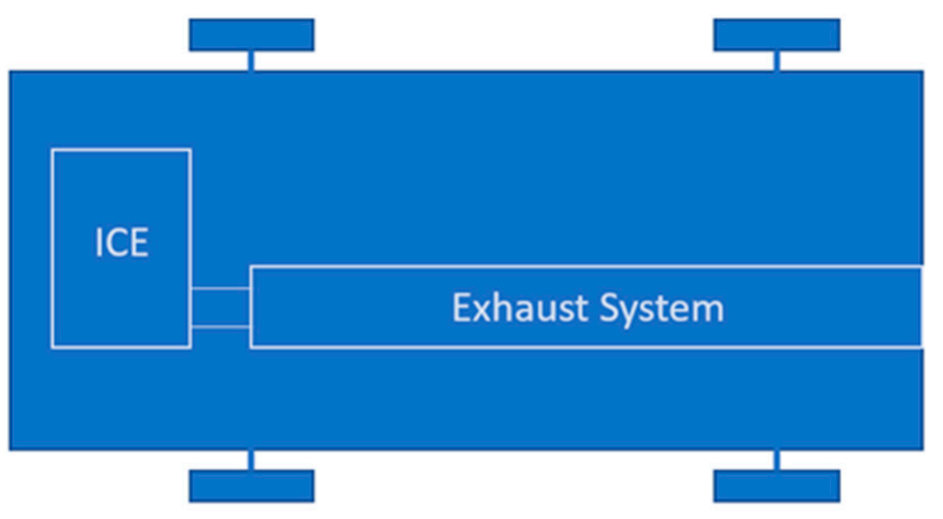

Figure 10. Basic layout of an ICE vehicle, highlighting the engine and exhaust system. 
To professionally complete a retrofit process, by utilising engineering principles, a laser scan of the engine bay and underside of the chassis can be completed, to highlight the layout and dimensions.

\subsection{Benefits}

After completion of a retrofit and the fuel type of a vehicle is converted to electricity, there are several benefits that could potentially be gained, similar to a newly manufactured electric vehicle. These include being able to drive in clean air zones (CAZs), ultra-low emission zones (ULEZs), and zero emission zones (ZEZs) without being charged. Additionally, the vehicles will receive a discount on congestion charges in London, following a successful application to provide the necessary details of the vehicle [90]. There are currently several zones, and plans for many new zones, throughout the UK, therefore highlighting the potential benefits for drivers of retrofitted vehicles. For example, there are CAZs in operation in Bath (class C) and Birmingham (class D), as well as a zone in Portsmouth beginning operation later in 2021 [91]. The other expected zones are in Bristol, Bradford, Leicester, Manchester, Newcastle, and Sheffield [92], therefore covering several major cities in England.

Table 3 below highlights the daily costs for a diesel van- $£ 9$ and $£ 8$ - compared to an electric van - no charge-in the two CAZs, as calculated by the online 'CAZ vehicle check' system [93]. Hence, for a vehicle that is travelling into one of these zones regularly, the costs for a diesel model quickly accumulate-for example, visiting the zone 5 days a week results in a weekly charge of $£ 45$ (Bath) or $£ 40$ (Birmingham), which could equate to a yearly cost of over $£ 2000$ in either area. In comparison, the electric model would pay no charges, which highlights significant potential savings. As retrofit systems accredited by CVRAS, including electric repowers, are already included in the CAZ exemption list, it is likely that vehicles accredited by a new and updated scheme, specifically for electric retrofits, would be included in this exemption.

Table 3. Table highlighting the daily costs for different vehicle models in CAZs [93].

\begin{tabular}{ccc}
\hline & \multicolumn{2}{c}{ CAZ Charge Per Day (£) } \\
\hline Vehicle Details & Bath & Birmingham \\
\hline VW Transporter (2.5 Diesel, 2001) & 9 & 8 \\
\hline VW e-Transporter (Electric, 2021) & 0 & 0 \\
\hline
\end{tabular}

On 25 October 2021, there was a vast expansion of the ultra-low emission zone in London, and therefore many more vehicles will be required to pay the daily charge of $£ 12.50$ (private cars, vans, motorcycles, mopeds, and taxis) or $£ 100$ (buses, coaches, and heavy goods vehicles (HGVs)) unless they are exempt from the charges [94]. Many London boroughs have been affected, with a large difference between the previous and new zones [95]. As discussed with CAZs, regularly visiting the ULEZ would incur significant costs for non-exempt vehicles-potentially over $£ 3000$ per year for cars, vans, motorcycles, and taxis, or over $£ 25,000$ per year for buses, coaches, and HGVs, based on visiting 5 days per week. Thus, switching to a vehicle meeting ULEZ standards would provide large savings for regular users, potentially making the cost of a new vehicle more economically viable in the long term. The emissions standards for the ULEZ are the same as for the CAZs, and there are also some other exemptions, such as for residents, vehicles for disabled people, taxis, historic vehicles, military vehicles, and specialist agricultural vehicles [94].

\subsection{Current Retrofit Practice}

In the UK, there are many retrofit companies offering services to convert ICE vehicles to electric drivetrains, with a large price variation. There have been approximately 8000 diesel buses retrofitted with exhaust after-treatment systems [96], but now several companies are offering fully electric retrofits for buses, considered to be a "cost-effective viable alternative 
to buying new electric buses" [97]. It is noted that a brand-new electric double-decker bus would cost around $£ 400,000$, with a delivery time of up to a year, whereas a retrofit would only cost $£ 200,000$, with Equipmake, a bus retrofit company, estimating that they could convert 5 diesel buses to electric powertrains per week [98]. Another company, Magnetic Systems Technology, has previously converted a city sightseeing bus to electric, providing annual environmental savings of 33 tonnes of $\mathrm{CO}_{2}$ and $535 \mathrm{~kg}$ of nitrogen oxides $\left(\mathrm{NO}_{\mathrm{x}}\right)$, as well as an annual cost saving of $£ 20,000$ due to using electricity instead of diesel [99].

A selection of current car and van retrofit companies in the UK are shown in Table 4, highlighting a price range of between $£ 18,000$ (ex. VAT) and $£ 500,000$, which suggests that varying amounts of work are being undertaken for the different conversions. As a comparison, a report states that, in Germany, retrofitting of smaller cars costs about $€ 8000(\sim £ 6800)$ and $€ 13,000$ to $€ 15,000$ ( $£ 11,000$ to $£ 12,700)$ for mid-size passenger cars $[19,100]$. Several of these companies are also selling conversion kits and components, which would allow members of the public to complete 'private' conversions. For new electric cars, prices can be similar to retrofit conversion costs, as, for example, the Nissan Leaf Acenta costs $£ 25,995$ [101] and the Peugeot e-208 costs $£ 27,225$ [102]. Therefore, for smaller cars, it is not currently as cost-effective to retrofit instead of buying a new EV, like it is for buses.

Table 4. Table highlighting a range of current retrofit companies. (N.B: Some prices were sourced from press articles as they were not supplied on the company websites.).

\begin{tabular}{|c|c|c|c|c|}
\hline Company Name & Type of Vehicles & Costs $(£)$ & Additional Information & References \\
\hline Electric Classic Cars & Classic cars & From 22,000 & Also sell kits and components. & {$[103,104]$} \\
\hline Zero EV & Cars & $\begin{array}{l}\text { Kits from } 15,000 \text { to } \\
65,000\end{array}$ & Also sell kits and components. & [105] \\
\hline Falcon Electric & Classic cars & From $18,000+$ VAT & $\begin{array}{l}\text { Lowest cost conversion uses } \\
\text { reconditioned parts. }\end{array}$ & [106] \\
\hline eDub Conversions & $\begin{array}{l}\text { VW campervans and } \\
\text { classic cars }\end{array}$ & $40,000-60,000$ & Sell components too. & [107] \\
\hline Electron Garage & Classic cars & From 20,000 & EV repairs too. & [108] \\
\hline Electrogenic & Classic cars and vans & From $\sim 30,000+$ VAT & & {$[109,110]$} \\
\hline London Electric Cars & $\begin{array}{c}\text { Classic vehicles (Mini, } \\
\text { Land Rover, Morris } \\
\text { Minor) }\end{array}$ & From 20,000 & Developing conversion kits. & [111] \\
\hline Everrati & Classic and iconic cars & $150,000-295,000$ & Online vehicle configurator. & [112] \\
\hline Lunaz & Classic cars & $245,000-500,000$ & $\begin{array}{l}\text { Powertrain designed and } \\
\text { engineered in-house. }\end{array}$ & {$[113,114]$} \\
\hline RBW Classic Electric Cars & Classic sports cars & From 90,000 & Online customisation builder. & [115] \\
\hline
\end{tabular}

The provenance of parts differs between companies, with some using reconditioned parts [106] to keep costs down. Furthermore, it has been reported that batteries are being used from vehicles that have been 'written-off' through an insurance claim, often from Tesla vehicles [104]. In particular, Electric Classic Cars (ECC) often use these batteries, or batteries that have previously been used for testing, produced by Tesla or LG Chem [104]. These batteries can be obtained at a lower cost and therefore can reduce the overall cost of conversion, although they may have a reduced lifespan and potentially could be damaged, which could lead to failure at a later date.

It is also stated that because the chassis and structural integrity of the vehicle are usually not affected, an Individual Vehicle Approval (IVA) test is not required, and, due to the lack of exhaust on the new system, an emissions test is not needed either [104]. Furthermore, if the vehicle is a classic, then it is likely to be MOT exempt, anyway, and, therefore, the only requirement is to notify the DVLA of the change to an electric drivetrain [104]. Guidance from the Department for Transport states that classic vehicles are only MOT 
exempt if they have not undergone a 'substantial change' within the last 30 years, with "alternative original equipment engines ... not considered to be a substantial change" [116]. This highlights the uncertainty of the criteria and process, especially as a conversion to an electric drivetrain is not mentioned in the guidance.

\subsection{Current Accreditation Schemes}

In the UK, accreditation schemes have been, and are currently, used for vehicle alterations similar to an electric retrofit, relating to emissions and fuel types.

\subsubsection{Clean Vehicle Retrofit Accreditation Scheme (CVRAS)}

The Energy Saving Trust currently provides an accreditation scheme-the Clean Vehicle Retrofit Accreditation Scheme (CVRAS) — which "certifies retrofit technologies that meet UK Government standards", aiming to address air pollution emissions from vehicles and support CAZs [117]. A CVRAS register is available online, which highlights the emission reduction systems, supplied by approved companies that are suitable for a specific vehicle, following the input of vehicle details [117]. The approved manufacturers mainly offer exhaust after-treatment systems, such as diesel particulate filter (DPF) and selective catalytic reduction (SCR) technologies, although there are also re-powering options, which involves replacing the current engine with a new, lower-emission engine or with an electric drivetrain [117].

The full process for the CVRAS is shown in Figure 11, highlighting the different stages that have to be undertaken, from the initial company audit, to the final retrofitted vehicle which will be linked to the automatic number plate recognition (ANPR) camera systems and become exempt from charges in restricted, low emission zones [96].

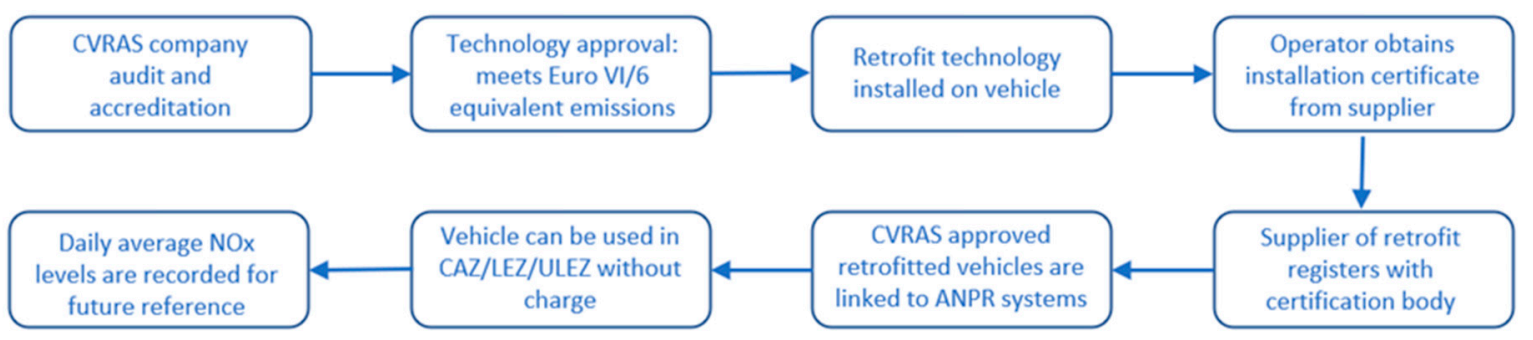

Figure 11. CVRAS process diagram, redrawn from [96].

With this scheme, the technology is checked and approved, however, the installers are trained and certified by the system supplier; the operator gains a certificate of installation from the supplier, but it is not approved by an independent body, which would be a sensible additional measure for electric retrofits. For exhaust after-treatment systems, which are most prevalent in the CVRAS, this limitation is less of a concern than it is for electric retrofits. This is because an electric retrofit affects the whole control of the vehicle, compared to just the exhaust system, and with a considerable number of companies now offering retrofits, it highlights the need for updated regulations, or an updated scheme, to ensure robust and reliable retrofit conversions.

SCR involves injecting 'AdBlue', containing urea, into the exhaust system [118] to cause a chemical reaction converting NOx into nitrogen and water vapour, which leave the tailpipe with a small amount of nitrous oxide [96]. The system is often fitted after a DPF, which, therefore, has already trapped particulate matter emissions. The operation of the system depends on the exhaust gas temperature, which is typically $200-450{ }^{\circ} \mathrm{C}$, but can be from $150{ }^{\circ} \mathrm{C}$, for urea (AdBlue) injection [96].

SCR systems are capable of reducing the amount of NOx released into the atmosphere by more than $95 \%$ [119], which benefits both the environment and human health, as the emissions cause acid rain [120], photochemical smog [121], and harmful respiratory issues [122]. 
In comparison to converting the fuel type of an ICE vehicle to electric, these systems are relatively simple to implement, as they only affect the exhaust system and not the whole drivetrain. The systems are utilised by over 8000 buses in the UK, highlighting the uptake of the technology following years of development [96].

Other technologies include 'Diesel Euro VI repowers', replacing the current engine with a new Euro VI certified engine and an exhaust after-treatment system, which meets requirements of the Euro VI emissions standards, in addition to improved fuel consumption and extended lifespan, due to the new engine [96]. Furthermore, a liquefied petroleum gas (LPG) conversion involves converting a petrol engine to use LPG as the engine fuel, or replacing a diesel engine with an adapted petrol engine that utilises LPG [96]. Utilising LPG reduces $\mathrm{CO}_{2}$ and NOx emissions in comparison to petrol and diesel vehicles [123].

The 'Low Emission Zone Retrofit Fund' is used in Scotland to provide grants for small businesses, within a 20-km distance of a planned low emission zone, to retrofit their current, non-compliant vehicles, with CVRAS-approved technologies [124]. Zones are planned to be introduced in Glasgow, Edinburgh, Aberdeen, and Dundee in the first half of 2022 [124], therefore affecting a large number of vehicles in Scotland. The grants can cover up to $80 \%$ of the cost of the retrofit conversion, providing up to $£ 5000$ for the installation of exhaust after-treatment systems on light commercial vehicles and wheelchair accessible taxis, up to $£ 10,000$ for a re-powering system for wheelchair accessible taxis, or up to $£ 16,000$ for HGVs or refuse collection vehicles [124].

\subsubsection{LPG Conversion Accreditation Scheme}

In order to ensure that these conversions meet a good level of quality and safety, UKLPG accredit the work of companies to provide them the status of an 'Approved Autogas Installer' [125]. There is a UKLPG vehicle register, which acts as an online database to highlight the vehicles that have been converted to LPG, after being submitted to the system by the approved installers [126]. To become an approved installer, the company must have nominated technicians who have certain levels of experience and have completed relevant training, and must undergo an inspection to gain a certificate and register access, if successful [126].

The fundamentals of this scheme, such as utilising approved installers, with experienced technicians, could be replicated for an electric retrofit scheme, to ensure a good standard of practice is met. Both of the above schemes highlight that accreditation has previously been required, and implemented, for similar technologies to electric retrofits, allowing consumers to obtain a safe, assessed end product.

\subsection{Government Guidance on Electric Retrofits}

Governmental bodies in the UK have produced guidance regarding changing the officially registered fuel type of a vehicle, as is needed to ensure that a retrofitted vehicle is identified as an EV. Currently, this process, according to the DVLA guidance, is to provide a receipt showing that a new engine has been fitted or to provide confirmation on headed paper from the garage of the work completed to convert an existing engine [127]. Furthermore, currently, there is no mention of an engine change under the list of 'changes that may need inspection', which includes wheel plan, body type, vehicle identification number, chassis number, and frame number (motorbikes), instead [127]. Therefore, under the current process, there is potential for varying levels of practice to be utilised.

The tax band cannot be changed simply via an updated V5C document (a vehicle log book), though, as this requires a separate process, involving the submission of a V70 form, alongside the altered V5C, current MOT certificate (if the vehicle is not exempt), and written proof of the change of fuel type, such as a garage receipt, to the DVLA [128]. For buses and lorries, a plating or weight certificate must also be submitted, and a certificate of initial fitness is also required for buses [128]. It is stated that the DVLA will confirm the change and an updated V5C will be sent to the owner [128]. 
The DVLA provide a point scoring system to determine whether a vehicle is classed as a 'radically altered vehicle', which therefore must undertake a re-registration process [129]. There is an overall number of 14 points for an unmodified vehicle, but if parts are changed, their allocated points, as shown in Table 5, are deducted from the overall total. If the total number is reduced below 8 points, then the re-registration process is required [129]. In regard to an electric retrofit, the modifications would include the engine (1 point) and the transmission ( 2 points), with the potential for the steering assembly to be also changed ( 2 points). This, therefore, would only reduce the overall total to 11 or 9 points, respectively, which therefore would not trigger the re-registration process.

Table 5. 'Radically altered vehicle' point scoring system [129].

\begin{tabular}{cc}
\hline Part & Points \\
\hline $\begin{array}{c}\text { Chassis, monocoque bodyshell (body and chassis as one unit) or } \\
\text { frame-original or new and unmodified (direct from manufacturer) }\end{array}$ & 5 \\
\hline Suspension (front and rear)-original & 2 \\
\hline Axles (both)-original & 2 \\
\hline Transmission-original & 2 \\
\hline Steering assembly-original & 2 \\
\hline Engine-original & 1 \\
\hline
\end{tabular}

For buses, as a public service vehicle, there is a requirement to complete and submit a 'VTP5' form to notify the DVSA of an alteration to the vehicle [130]. This form requires details of the vehicle and the notifiable alteration that has been made, as well as any changes to the carrying capacity, the type of suspension, and the unladen vehicle weight [131]. It also includes logistical details for an examination of the vehicle, which would be carried out, although there are no details of the specific procedure utilised [131]. In further guidance, there are details of many regulations and standards, utilised for new vehicles, which must be complied with for re-approval of the vehicle, such as 'The Public Service Vehicles (Carrying Capacity) Regulations 1984' and 'The Road Vehicles (Authorised Weight) Regulations 1998 [132]. Although these are necessary regulations to ensure the safety of the vehicle, and may be affected by an electric retrofit, they do not specifically regulate the electric drivetrain system being installed.

\section{Results}

As a result of the literature research and industrial visits, information was collected regarding the process required to register retrofitted vehicles as electric and the procedures undertaken by different retrofit companies to complete retrofit conversions safely and to a good standard.

\subsection{Fuel Type Change}

For passenger vehicles, such as cars and vans, Figure 12 represents the apparent method of informing the DVLA of a vehicle that has been retrofitted, thus changing the fuel type to 'electricity'. 


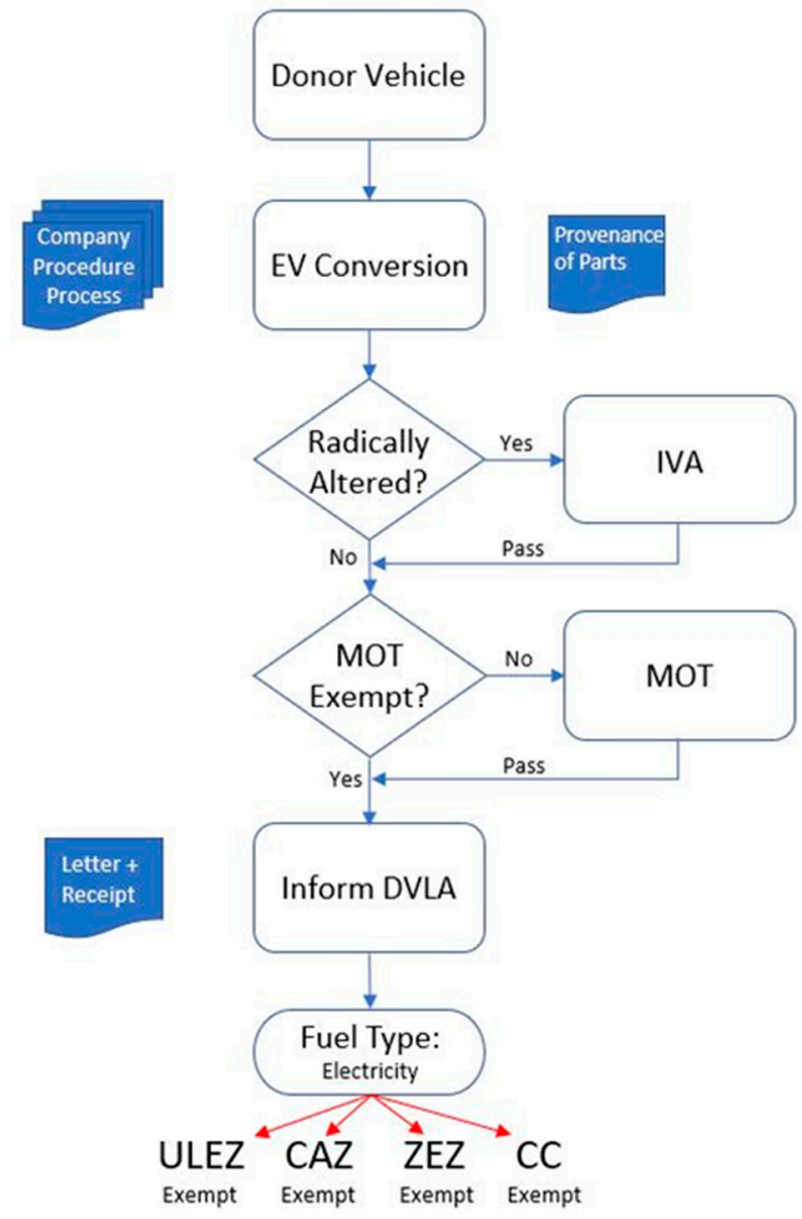

Figure 12. Schematic highlighting the apparent process of converting a car or van to a fuel type of 'electricity'. CC: Congestion charge.

Due to the 'radically altered' points scoring system, the majority of electric retrofitted vehicles do not trigger this and therefore are not required to undertake the IVA process. Following this, the only other level of testing is an MOT, which some vehicles are possibly exempt from. If an MOT is required, the level of guidance for testers is relatively limitedavoiding HV components and wiring, not interfering with the HV system, and abandoning the test if any orange cables are damaged, are all suggested [133]-and the test relies on a lot of visual inspection, as parts cannot be removed. To then inform the DVLA of this change, a receipt of the work completed or a headed letter from the garage completing the work must be supplied. Therefore, unlike new vehicle production, there are no specific checks to ensure electrical safety or adequate handling, etc., before the vehicle can be driving on public highways again.

Changing the fuel type of a bus to 'electricity' requires a more rigorous process, though, as it includes test reports and an inspection at a test station. This is shown by the schematic below, in Figure 13, highlighting the VTP5 form, which can be submitted to notify the DVSA of an alteration to the vehicle, requiring documentation to be submitted. Several key regulations are stated, as an example of what supporting evidence could be included, such as a tilt justification report or braking test information, to prove that the vehicle is suitable to be used safely on public roads. An inspection may still be required after this to examine and check the work that has been completed, in line with the submitted information, before signing the vehicle off, to be returned to service. The V5C document of the vehicle must then be updated with details of the new fuel type and vehicle weight, before submission to the DVLA for it to be updated on relevant registers. 


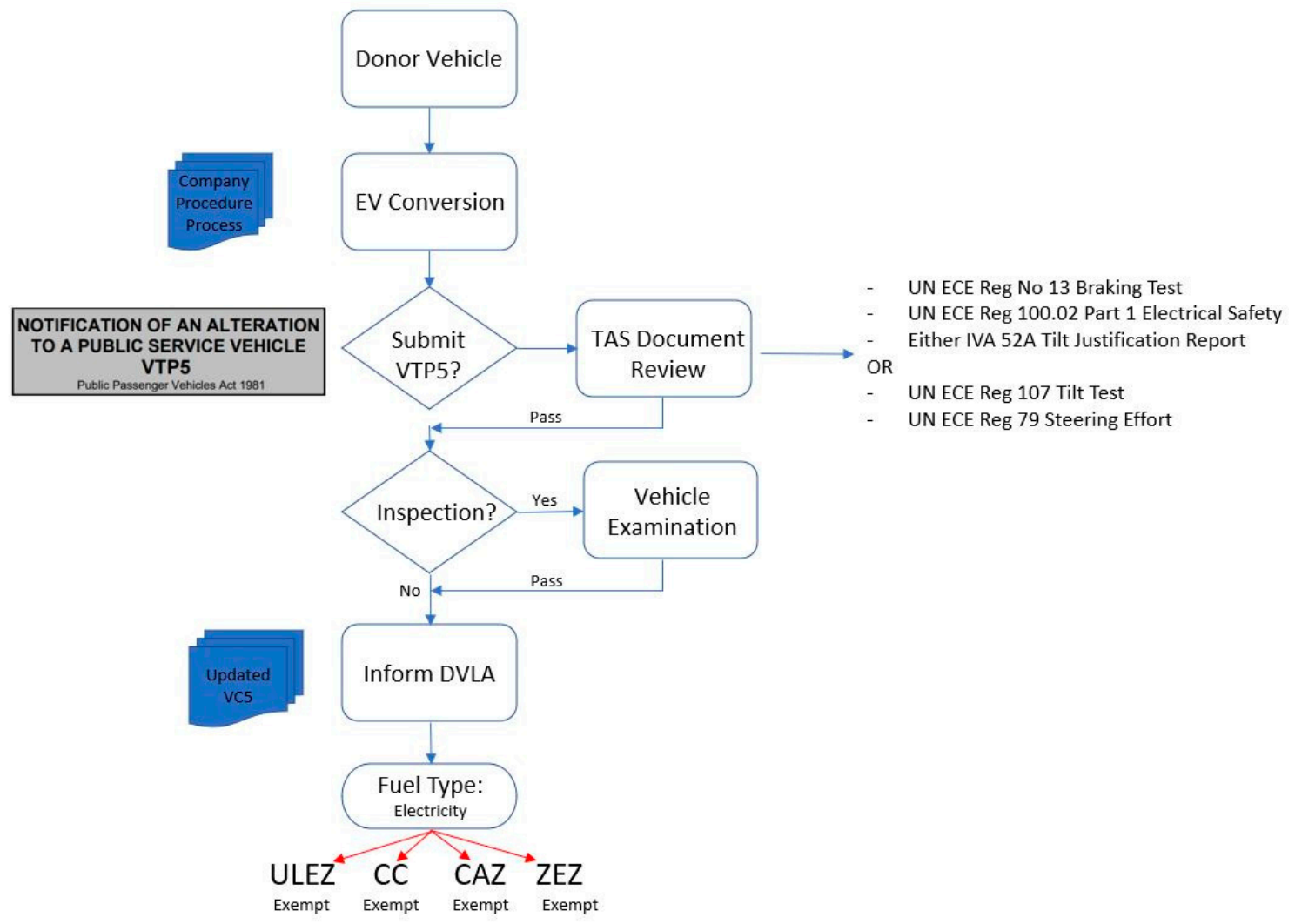

Figure 13. Schematic highlighting the apparent process of converting a bus to a fuel type of 'electricity'. CC: Congestion charge.

The above processes were reviewed and discussed in meetings with relevant government departments.

The details of several retrofitted vehicles were entered into the DVLA online system to check their details [134], which highlighted that the $\mathrm{CO}_{2}$ emissions were not registered as $0 \mathrm{~g} / \mathrm{km}$, as would be the case for a new EV. For example, a converted VW Beetle showed a new fuel type of 'Electricity', but its $\mathrm{CO}_{2}$ emissions were shown as 'Not available', whereas a converted Porsche Boxster, showed a new fuel type of 'Electricity' with its original $\mathrm{CO}_{2}$ emissions of ' $223 \mathrm{~g} / \mathrm{km}^{\prime}$ ', as shown below in Table 6 . Additionally, utilising the CAZ online system highlighted that both of these vehicles would be exempt from charges in all CAZs [93], which suggests that their system focuses on the registered fuel type of the vehicle, not the $\mathrm{CO}_{2}$ emissions.

Table 6. Vehicle details of two retrofitted vehicles, highlighting the difference in information held by the DVLA. Information obtained from: [134].

\begin{tabular}{ccc}
\hline Vehicle Make & Volkswagen & Porsche \\
\hline Date of First Registration & January 1965 & May 2004 \\
\hline Year of Manufacture & 1965 & 2004 \\
\hline CO $_{2}$ Emissions & Not available & $233 \mathrm{~g} / \mathrm{km}$ \\
\hline Fuel Type & Electricity & Electricity \\
\hline
\end{tabular}

\subsection{Industrial Survey}

Visiting several EV retrofit companies, based in England, facilitated discussions regarding the processes being utilised and the regulations or standards being met by each company. Company names have been anonymised here for confidentiality purposes. 


\subsubsection{Company A}

Company A complete regular restoration work to the structure of the donor vehicle at the start, resolving any issues to the chassis, such as rust. Staff members are HV trained to a basic standard, and it is proposed that accredited partners will be supplied with assembly guidance for conversion kits, as well as having a trained/qualified technician. This is because the company carries out the engineering work (design and testing) themselves, whilst a partner company fits the system. With a small team of engineers, they can carry out design work, as well as testing and simulations with the aim of achieving the best practice and a high standard. Technical specifications and design verification plans are utilised, as well as exploring critical failures and assessing functional safety. A development vehicle has been produced, which can be utilised and tested, to reassess any processes, if necessary. CAD software is utilised to design several parts, which can be tested using finite element analysis (FEA) software, to ensure they will be suitable, for example, enduring necessary stresses. To protect parts produced, powder coating or corrosion-resistant coatings are utilised. The provenance of parts varies, with batteries sourced new from a supplier, but a second-hand motor utilised-following testing. The company had a similar understanding of the process to change the fuel type of a retrofitted car, as shown in Figure 12.

\subsubsection{Company B}

Company B undertake a chassis assessment, for rust or damage, at the start and complete necessary repairs. A large amount of testing is completed to ensure appropriate safety levels are met, with a feasibility study undertaken to assess structural integrity. This includes producing a CAD model of the chassis and the batteries and then simulating it, using FEA, to highlight the ability of the chassis and axles, for example. Additionally, regulations are met, through testing, to provide supporting evidence to submit with the change of fuel type information. These regulations include: UNECE Regulation 13 (braking test), Regulation 79 (steering effort), and Regulation 107 (tilt test) are considered. However, an IVA tilt justification report may be submitted instead of the tilt test. Rigorous battery testing is completed at pack level, as battery modules are purchased, including 8 different tests: Vibration, thermal shock cycling, mechanical shock, fire resistance, external short circuit, overcharge, over-discharge, and standard charge/discharge cycle. For retrofits, bespoke battery packs are often required to meet the specific requirements of the vehicle. It was suggested that it is sensible to meet Regulation 100 Part 1, however, although some of it could be met, it is too difficult to meet Part 2 .

In regard to functional safety, the core documents of ISO 26262 are aimed to be completed, as it is considered unrealistic to complete full functional safety for retrofits, as would be required for a new vehicle, due to time and financial constraints. A dedicated safety engineer is employed and the following process, shown in Figure 14, is utilised.

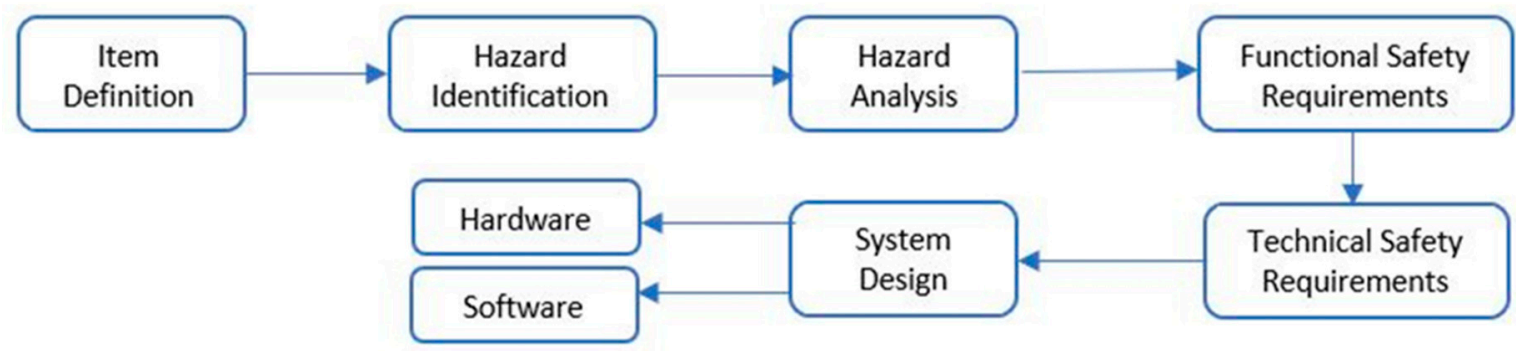

Figure 14. Functional safety process diagram.

Hazards are identified, as well as potential failures for the intended functions, and then hazard ratings can be calculated to obtain an Automotive Safety Integrity Level, which can be used to determine the level of engineering required. Safety goals, and thus safety requirements, can be produced, however, it is potentially very subjective, as they are self-defined. 
Parts that are purchased are certified, however, the majority are manufactured by the company themselves, adhering to their own standards. Following a retrofit conversion, a warranty of 5 years on the parts installed is suggested, and a telematics system is to be installed to monitor usage.

The company had a similar understanding of the process to change the fuel type of a bus, as shown in Figure 13. Additionally, it was suggested that a safety case document could be provided as a minimum, with the core principles of ISO 26262 being considered, and an auditing system, like ISO 9001, could be utilised so companies would have certificates to highlight the processes they follow.

\subsubsection{Company C}

Company $\mathrm{C}$ carry out necessary restoration work at the start, ensuring issues, such as rust, are treated. A 3D scan of the vehicle is carried out, to aid the CAD work, as well as measuring the vehicle in the workshop. Framework and/or mounting systems to support the battery packs and motor are manufactured following this. Weight distribution is considered and, thus, a split battery pack is utilised to spread the loading appropriately. Battery packs are built from purchased modules, whilst an off-the-shelf engine control unit is utilised with a core set of code provided (meeting ISO 26262), although extra functionality is added where needed. Power distribution units and control software are also developed. Many components are purchased, though, with direct supplies for CE-marked products from OEMs, which are provided with installation guidelines.

Regarding safety, ground fault protection, brake balance (due to regenerative braking), and electrical interference were discussed, with an overall aim of best practice, highlighting that ISO 26262 could not be met in full, although the main principles of this and Regulation 100 are considered. As there are plans to sell vehicles overseas, other regulations would have to be considered, such as TUV regulations within Europe. A 'type approval' process was considered, whereby a standardised process for certain models can be approved, by using the same components, for example. The placement of components within the vehicle is considered to ensure that they are located sensibly for crash scenarios. A $12 \mathrm{~V}$ power controller is installed and it was recognised that the control system needs to be able to inform the driver of necessary information. The testing of a physical vehicle is carried out at the Millbrook vehicle testing centre, in particular, to understand when a vehicle is derating, so that issues can be mitigated. The company had a similar understanding of the process to change the fuel type of a car, as shown in Figure 12. Additionally, it was suggested that a physical inspection could be completed, with supporting documentation submitted too, considering the provenance of parts, axle loads, and weight distribution, in addition to proof of CAD and FEA work.

\subsubsection{Exhibition}

At the ITT Hub exhibition, on the 1 July 2021, at Farnborough International Exhibition \& Conference Centre, new EVs were on display, showcasing the electric drivetrain systems, which allowed comparisons to be made with ICE vehicles. Several examples utilised the same bodyshell as the previous ICE version of the vehicle, but with a new electric drivetrain. For example, the Mercedes Benz E-citaro bus, uses the same bodyshell as the previous diesel version, placing 4 battery packs in the back of the vehicle, where the engine would have been, and up to 8 battery packs in the roof. The rear bay, containing the four battery packs, is shown in Figure 15, also highlighting the orange HV cabling utilised. 


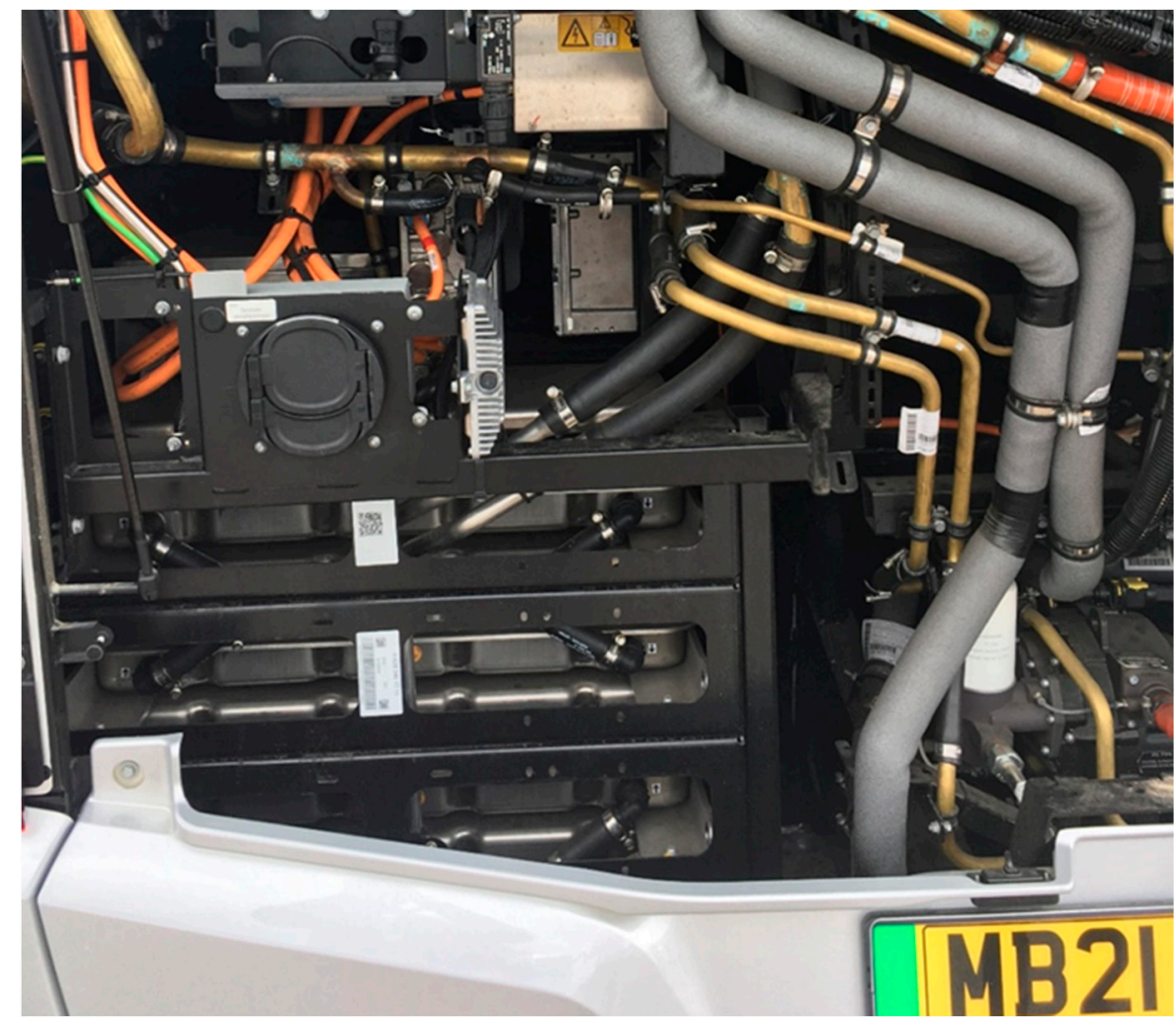

Figure 15. Mercedes Benz E-citaro electric bus. Photo taken by the author.

Additionally, the Fiat E-ducato and the Maxus eDeliver 9 both utilise the same shell as their previous diesel versions, installing the electric motor in the engine bay area and the battery packs along the underside of the chassis. Regenerative braking is included on both vehicles; hence the braking systems are adjusted to incorporate it.

A Mitsubishi Fuso E-canter was displayed, highlighting more of the electric drivetrain system, with orange HV cabling fixed along the chassis, and sealed battery packs, preventing ingress of debris or water, as shown below in Figure 16. This highlights the standard of work required for a new EV, providing good guidance for electric retrofits, although it is probably unfeasible to meet all of the same standards, due to financial and time constraints.

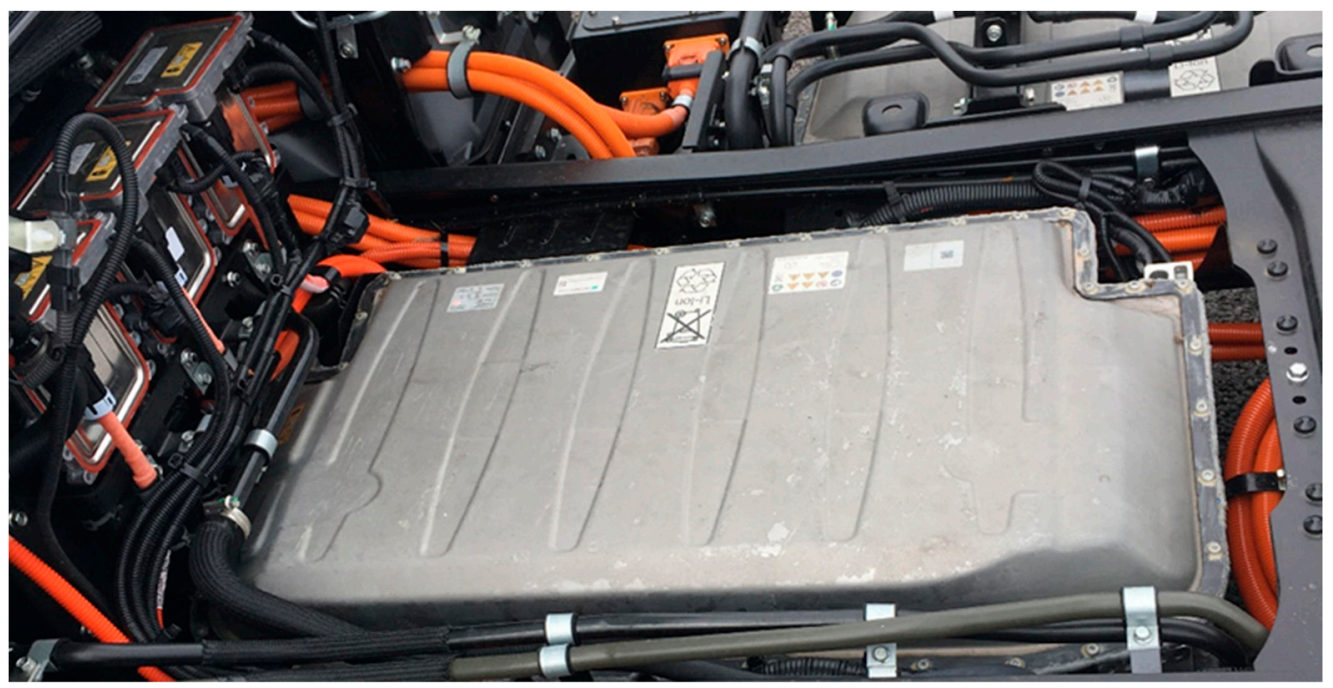

Figure 16. Chassis layout of a Mitsubishi Fuso E-canter, highlighting a sealed battery pack and organised orange HV cabling. Photo taken by the author. 


\section{Discussion}

The results and analysis above highlight the simplicity of the apparent administrative process to convert the registered fuel type of a car or van to electricity, requiring a receipt or headed letter from the garage, with no evident inspections or checks to ensure that the work has been completed safely. As an electric retrofit changes the drivetrain, which propels the vehicle, not just the exhaust system, like an SCR retrofit, and therefore controls whether the vehicle is stationary or moving, this could pose a potentially significant safety hazard to the driver and other road users. Furthermore, as discussed previously, there are many safety aspects to be considered with an electric drivetrain system, such as the lithium-ion batteries, which have the potential to cause considerable fires, if they are damaged, not professionally designed and tested, or not properly regulated by a management system. Due to the potential inadequacy of regulations and inspections, the provenance of these parts can vary greatly, with the potential for components to be used from written-off (previously crashed) vehicles, which may be damaged. If this damage exacerbates over time, such as a crack propagating, the result can be a significant fire, especially if an adequate control or management system is not implemented. This highlights the need for a more rigorous process to ensure that safety is at the forefront of these conversions, reducing the risk of failures later on.

The apparent process to convert the fuel type of a bus to electricity highlights more rigorous stages, which involve the submission of details of changes, ideally with supporting evidence that the vehicle meets certain regulations, and an inspection or examination of the vehicle. The process still appears prone to variation, without stipulation of minimum requirements that need to be met, so therefore the retrofit conversions completed and signed off could be to varying standards of practice.

The information provided by the DVLA online highlights that retrofitted vehicles have successfully been converted to a fuel type of electricity and that they are now exempt from charges in CAZs, therefore gaining benefits of an EV. These conversions, however, have potentially been completed without any inspection or any proof that the work has been completed to a good standard, which highlights an area of the process for potential improvement.

Visits to retrofit companies highlighted themes of practice, such as undertaking general restoration work to the donor vehicle, and using CAD software to simulate and test the proposed designs and layouts, to ensure they would be suitable. All of the companies considered weight distribution, and the subsequent loads, of the new system. Company B undertook rigorous battery testing and focused largely on regulations and functional safety, aiming for the main principles of ISO26262. The other two companies showed consideration to ISO26262 and Regulation 100, however, the extent to which these were adhered to was not as clear. Additionally, the provenance of parts utilised by the companies varied, with one company producing the majority of parts themselves, one company aiming to purchase the majority of their parts new and one company utilising a mix of new and second-life parts. Within the 'Current Retrofit Practice' section previously, a wider variety of companies were shown, highlighting another company openly stating their use of reconditioned parts. The vast range in price of conversions was also shown, which depicts the budget that companies would have to be able to complete the work; if a low-cost conversion is offered, then companies may need to decrease costs in other ways, such as utilising cheaper parts.

All the companies had a similar understanding of the apparent processes to convert the registered fuel type of vehicles to electricity, shown in Figure 16, whether for a car, van, or bus. This suggests that these are relatively accurate and, thus, the seemingly very simple car and van process is likely being utilised to convert vehicles currently. There may be a requirement for an MOT test to be completed, however, changes to the process may be required for EV retrofits, as currently it is mainly a visual inspection and parts are not removed. Furthermore, as this is a new technology compared to ICE vehicles, MOT testers may require additional training, which could incorporate retrofit conversions too. 
Vehicles at the ITT Hub exhibition further highlight the ability to convert current ICE vehicles to electric, as several examples show how the bodyshell of the previous diesel version/model was utilised for the electric version. This suggests that there is adequate space to fit the electric drivetrain parts, after removing the ICE components, and that it can be done without diminishing the safety of the vehicle, as these new vehicles are subject to a multitude of regulations and standards. This highlights a very high standard of practice that can be compared to with retrofits.

There are many benefits of an EV currently, from reduced GHG emissions helping to alleviate the detrimental effect of the transport sector on the environment, to charge exemptions in several major cities, reduced driving costs and lower maintenance. There has been a considerable increase in the number of EVs sold in the UK and globally, with charging infrastructure and battery production greatly advancing too. This highlights a transition towards the technology, especially given legislation in the UK to ban the sale of ICE vehicles. Therefore, alternative processes to reach these benefits and be part of the transition will not only be prevalent but also beneficial. There are several companies now offering electric retrofit conversions in the UK, with varying price ranges and levels of practice, allowing vehicle owners, and operators, to keep vehicles on the road without being financially penalised. In particular, this is popular with vehicles of a high inherent value, such as buses and classic cars, as it is more economically viable. With a potentially vast uptake in this market, the limited regulations could be of concern, due to the potential for unreliable conversions and, thus, vehicles. Therefore, the requirement for regulations regarding electric retrofits is even greater, as the technology becomes more prevalent.

The current CVRAS does technically include electric retrofits, however, it is mainly aimed at SCR exhaust aftertreatment systems, and has limitations for retrofits, predominately the fact that an independent body does not check whether a system has been installed appropriately-instead, the supplier approves the installer, which is a major factor when replacing the drivetrain of a vehicle. Thus, it would be beneficial to introduce a new accreditation scheme that focuses on electric retrofits, setting necessary requirements. The concern of a new scheme or regulations is that if they are too rigorous then the electric retrofit market could become unviable, especially if they made the barriers to entry greater than for new EVs. For example, the financial cost of lots of testing to meet regulations could cause the conversion to be too expensive, reducing the demand considerably.

Furthermore, as highlighted previously in the report, the cost of an electric retrofit for cars starts at around $£ 18,000$ to $£ 20,000$, however, a small new electric car costs around $£ 26,000$, showing the similarity in costs. Therefore, several companies focus on more niche markets, such as classic vehicles or buses, as the process can be more financially viable. For example, a retrofit bus conversion can cost half the price of a new electric bus, which makes it a more economically worthwhile choice. However, over time, with a predicted uptake in EV production and sales, the parts for an electric drivetrain will likely become cheaper, especially with plans for mass production of batteries in gigafactories, due to economies of scale. This could, therefore, make these lower-cost retrofits more affordable, due to the cheaper parts, although it could also make new EVs more affordable, depending on the profits aimed for by the OEMs producing them. A major benefit of retrofitting vehicles, though, is that it would reduce the number of vehicles required to be scrapped, compared to purchasing all new EVs, therefore having a significant environmental impact. If this was incentivised by the government, such as including electric retrofits in financial schemes such as the 'plug-in' grant, or creating alternative new schemes, there could be a much greater uptake. It would be beneficial for OEMs and electric retrofit companies to interact, as they may be able to save time and resources and work in collaboration to allow this process to operate more smoothly. For example, OEMs are likely to already have CAD drawings and specific details of their previously manufactured vehicles, which they could provide to retrofit companies, to prevent them having to repeat the same work when they are converting that vehicle, hence making the process more efficient. 
Although three companies were visited to witness industrial premises first-hand, these were mainly companies offering high-cost services. To strengthen the work, more companies could be assessed with a wider variety of procedures. Current processes for the conversion of the registered fuel type were obtained from available government literature and discussed in a couple of meetings with relevant bodies. However, further meetings would likely ascertain more details and may gain more clarity of the actual processes occurring. Therefore, the number of industrial visits and meetings with governmental bodies potentially limits the level of detail obtained, and the apparent lack of clarity limits the certainty of administrative processes. The paper focuses on UK-based companies only and thus could be explored internationally.

\section{Conclusions}

Electric retrofits have the potential to aid the transition to zero emission vehicles, decreasing the significant contribution to GHG emissions that the transport sector makes, as EVs can reduce GHG emissions by up to $90 \%$ compared to ICE vehicles and in addition to reducing climate change, vehicle owners can benefit from charge exemptions in major cities with potential savings of over $£ 2000$ per year, lower fuel costs, and reduced maintenance. Converting current vehicles could limit the scrappage and wastage of well-functioning vehicles that would result if only new BEVs were purchased, embracing the re-use principle of a circular economy. Additionally, the BEV technology could be adopted at a reasonable rate, whilst reducing the need to manufacture and market as many new BEVs in the immediate future.

The current administrative process to convert a fuel type to electricity for a car or van, following a retrofit conversion, appears to be simplistic, with current regulations that may not adequately cover the post-registration retrofit market. For buses, there appears to be a slightly more rigorous process, although the minimum requirements are not evident. A reasonable number of retrofit companies are now in the market, with a vast range of prices, offering a varying level of work, with differing conditions of parts. All companies that were visited had a similar understanding of the process to change fuel type and all displayed a level of engineering analysis that was completed during their retrofits, with some focusing on regulations more than others. The limited regulations suggest that, in comparison to new EVs, there may be an absence of specific checks to verify the electrical safety and adequate handling, etc. of a retrofitted vehicle, which could lead to failures later on. Therefore, the need for regulations regarding electric retrofit conversions is paramount and will only become more necessary as the market grows. As such, an accreditation scheme in the UK would be a recommended implementation, which could potentially be replicated in other countries, depending on the specific processes undertaken there. Further work is advised to determine the specific details of the criteria to be met, such as numerical values and defined tests.

In the future, it would be beneficial to undertake further discussions with the DVLA and DVSA to explore the potential of altering current, or introducing new, processes to assess the safety and quality of retrofit conversions before the change of fuel type is approved and the vehicle is allowed to be used on the road again. Additionally, discussions with the Motor Insurers' Bureau would be beneficial, as an accreditation scheme may result in insurance companies only insuring accredited retrofitted vehicles, therefore, removing the possibility of non-accredited, poorly converted vehicles being on the road.

Author Contributions: Conceptualization, R.W., A.G. and J.H., methodology, R.W., A.G. and J.H., software, R.W.; validation, R.W.; formal analysis, R.W.; investigation, R.W.; resources, R.W.; data curation, R.W., A.G.; Writing-original draft preparation, R.W.; writing-review and editing, R.W. and A.G.; visualization, A.G.; supervision, A.G. and J.H.; Project administration, A.G. and J.H.; Funding acquisition, A.G. All authors have read and agreed to the published version of the manuscript.

Funding: This research received no external funding.

Institutional Review Board Statement: Not applicable. 
Informed Consent Statement: Not applicable.

Data Availability Statement: Not applicable.

Acknowledgments: The authors would like to extend gratitude and appreciation to the Renewable Energy Department at the University of Exeter for performing this project.

Conflicts of Interest: The authors declare no conflict of interest.

\section{References}

1. IPCC. Climate Change 2021: The Physical Science Basis-Summary for Policymakers; Cambridge University Press: Cambridge, UK, 2021.

2. Ritchie, H.; Roser, M. $\mathrm{CO}_{2}$ and Greenhouse Gas Emissions. 1 August 2020. Available online: https:/ / ourworldindata.org/co2 -and-other-greenhouse-gas-emissions?source=post_page-----47fa6c394991---------------------\#licence (accessed on 6 December 2021).

3. International Energy Agency. Tracking Transport 2020; IEA: Paris, France, 2020.

4. Karki, A.; Phuyal, S.; Tuladhar, D.; Basnet, S.; Shrestha, B.P. Status of Pure Electric Vehicle Power Train Technology and Future Prospects. Appl. Syst. Innov. 2020, 3, 35. [CrossRef]

5. Küfeoğlu, S.; Hong, D.K.K. Emissions performance of electric vehicles: A case study from the United Kingdom. Appl. Energy 2020, 260, 114241. [CrossRef]

6. Verma, S.; Dwivedi, G.; Verma, P. Life cycle assessment of electric vehicles in comparison to combustion engine vehicles: A review. Mater. Today Proc. 2021, 46. [CrossRef]

7. Ghosh, A. Possibilities, Challenges for the Inclusion of the Electric Vehicle (EV) to Reduce the Carbon Footprint in the Transport Sector: A Review. Energies 2020, 13, 2602. [CrossRef]

8. Hou, F.; Chen, X.; Chen, X.; Yang, F.; Ma, Z.; Shining, Z. Comprehensive analysis method of determining global long-term GHG mitigation potential of passenger battery electric vehicles. J. Clean. Prod. 2021, 289, 959-6526. [CrossRef]

9. Albatayneh, A.; Assaf, M.N.; Alterman, D.; Jaradat, M. Comparison of the Overall Energy Efficiency for Internal Combustion Engine Vehicles and Electric Vehicles. Environ. Clim. Technol. 2020, 24, 669-680. [CrossRef]

10. Ayodele, B.V.; Mustapa, S.I. Life Cycle Cost Assessment of Electric Vehicles: A Review and Bibliometric Analysis. Sustainability 2020, 12, 2387. [CrossRef]

11. Department for Business, Energy and Industrial Strategy. UK Becomes First Major Economy to Pass Net Zero Emissions Law; UK Government: London, UK, 2019.

12. Thunberg, G. No One Is Too Small to Make a Difference; Penguin Books: London, UK, 2019.

13. National Geographic. Some Catastrophic Changes to the Climate Can Still Be Headed off. 9 August 2021. Available online: https:/ / www.nationalgeographic.com/environment/article/some-irreversible-changes-to-the-climate-can-still-be-headedoff-report-says (accessed on 9 August 2021).

14. Santos, G.; Rembalski, S. Do electric vehicles need subsidies in the UK? Energy Policy 2021, 149, 111890. [CrossRef]

15. Liu, X.; Sun, X.; Zheng, H.; Huang, D. Do policy incentives drive electric vehicle adoption? Evidence from China. Transp. Res. Part A Policy Pract. 2021, 150, 49-62. [CrossRef]

16. Wangsness, P.B.; Halse, A.H. The Impact of Electric Vehicle Density on Local Grid Costs. Energy J. 2021, 42, 5. [CrossRef]

17. International Energy Agency. Global EV Outlook 2021; IEA: Paris, France, 2021.

18. Logan, K.G.; Nelson, J.D.; Brand, C.; Hastings, A. Phasing in electric vehicles: Does policy focusing on operating emission achieve net zero emissions reduction objectives? Transp. Res. Part A Policy Pract. 2021, 152, 100-114. [CrossRef]

19. Hoeft, F. Internal combustion engine to electric vehicle retrofitting: Potential customer's needs, public perception and business model implications. Transp. Res. Interdiscip. Perspect. 2021, 9, 100330. [CrossRef]

20. de Santis, M.; Regis, F. Modeling, simulation, and techno-economic analysis of a retrofitted electric vehicle. In Proceedings of the 2021 IEEE International Conference on Environment and Electrical Engineering and 2021 IEEE Industrial and Commercial Power Systems Europe (EEEIC/I\&CPS Europe), Bari, Italy, 7-10 September 2021.

21. Innovation and Technology in Transport Hub. ITT Hub: Home. 2021. Available online: https://itthub.co.uk/ (accessed on 5 September 2021).

22. Department for Business, Energy \& Industrial Strategy. 2019 UK Greenhouse Gas Emissions, Final Figures—Statistical Release; UK Government: London, UK, 2021.

23. Department for Business, Energy \& Industrial Strategy. 2019 UK Greenhouse Gas Emissions: Final Figures—Data Tables; UK Government: London, UK, 2021.

24. Department for Transport. Bus Back Better; Department for Transport: London, UK, 2021.

25. Rapson, D.S.; Muehlegger, E. The Economics of Electric Vehicles; National Bureau of Economic Research: Cambridge, UK, 2021.

26. Goldie-Scot, L. A Behind the Scenes Take on Lithium-ion Battery Prices; BloombergNEF: New York, NY, USA, 2019.

27. Brandmayr, C.; Leung, R. Accelerating the Electric Vehicle Revolution: Why the UK Needs a ZEV Mandate; Green Alliance: London, UK, 2021.

28. Element Energy. Electric Cars: Calculating the Total Cost of Ownership for Consumers; BEUC: Cambridge, UK, 2021.

29. Department for Transport. Vehicle Licensing Statistics: 2021 Quarter 1 (Jan.-Mar.); UK Government: London, UK, 2021. 
30. Next Greencar. Electric Car Market Statistics. 2021. Available online: https://www.nextgreencar.com/electric-cars/statistics/ (accessed on 15 August 2021).

31. Baars, J.; Domenech, T.; Bleischwitz, R.; Melin, H.E.; Heidrich, O. Circular economy strategies for electric vehicle batteries reduce reliance on raw materials. Nat. Sustain. 2021, 4, 71-79. [CrossRef]

32. Sky News. Nissan Announces $£ 1$ bn 'Gigafactory' Boosting Electric Car Production and Creating Thousands of Jobs. 2021. Available online: https:/ / news.sky.com/story/nissan-to-unveil-new-sunderland-gigafactory-that-will-help-boost-electric-carproduction-12345950 (accessed on 22 July 2021).

33. BBC News. Nissan in Talks to Build Huge UK Battery Factory. 2021. Available online: https://www.bbc.co.uk/news/business57247758 (accessed on 26 June 2021).

34. BBC News. Gigafactories: Europe Tools up against US and Asia as a Car Battery Force. 2021. Available online: https: / / www.bbc.co.uk/news/business-57382472 (accessed on 26 June 2021).

35. Northvolt, A.B. Products-Lithium-Ion Cells. 2021. Available online: https:/ / northvolt.com/products (accessed on 22 July 2021 ).

36. Charged Electric Vehicles Magazine. CARB Proposes New Rules for Defining EV Battery Health. 2021. Available online: https:/ / chargedevs.com/newswire/carb-proposes-new-rules-for-defining-ev-battery-health/ (accessed on 15 August 2021).

37. FleetNews. Battery Health Reports Needed to Secure EV Residual Values. 2020. Available online: https://www.fleetnews.co. uk/news / car-industry-news/2020/06/04/battery-health-reports-needed-to-secure-ev-residual-values (accessed on 15 August 2021).

38. Tomaszewska, A.; Chu, Z.; Feng, X.; O’Kane, S.; Liu, X.; Chen, J. Lithium-ion battery fast charging: A review. Etransportation 2019, 1, 100011. [CrossRef]

39. Zap-Map. EV Charging Stats 2021. 2021. Available online: https:/ /www.zap-map.com/statistics/ (accessed on 6 August 2021).

40. Statista. Number of Petrol Stations in the United Kingdom (UK) 2000-2020. 10 February 2021. Available online: https: //www.statista.com/statistics/312331/number-of-petrol-stations-in-the-united-kingdom-uk/ (accessed on 7 August 2021).

41. OVO Energy. What's Stopping the 'Electric Vehicle Revolution'? 2017. Available online: https://www.ovoenergy.com/blog/ovonews/whats-stopping-the-electric-vehicle-revolution (accessed on 6 August 2021).

42. Arup. Creating a Sustainable Future for the Strategic Road Network in England. 2021. Available online: https://www.arup.com/ projects/highways-england-rapid-electric-vehicle-charge-points-programme (accessed on 6 August 2021).

43. Ellson, A. Owners of electric cars are struggling to get plugged in. The Times, 24 September 2016.

44. Kapustin, N.O.; Grushevenko, D.A. Long-term electric vehicles outlook and their potential impact on electric grid. Energy Policy 2020, 137, 111103. [CrossRef]

45. Office for National Statistics. Wind Energy in the UK: June 2021. 14 June 2021. Available online: https://www.ons.gov.uk/ economy/environmentalaccounts/articles/windenergyintheuk/june2021 (accessed on 7 August 2021).

46. Department for Business. Energy E Industrial Strategy, Energy Trends; UK Government: London, UK, 2021.

47. AutoCar. Road to 2030: How Much Electric Power Will We Need? 2021. Available online: https://www.autocar.co.uk/carnews/industry-news-tech\%2C-development-and-manufacturing/road-2030-how-much-electric-power-will-we (accessed on 24 August 2021).

48. Freschi, F.; Mitolo, M.; Tommasini, R. Electrical Safety of Plug-In Electric Vehicles: Shielding the Public from Shock. IEEE Ind. Appl. Mag. 2018, 24, 58-63. [CrossRef]

49. Finegan, D.P.; Darst, J.; Walker, W.; Li, Q.; Yang, C. Modelling and experiments to identify high-risk failure scenarios for testing the safety of lithium-ion cells. J. Power Sources 2019, 417, 29-41. [CrossRef]

50. Andersson, P.; Anderson, J.; Larsson, F.; Mellander, B.-E. Modelling of Thermal Events in Lithium-Ion Batteries. In Proceedings of the ESFSS 2015 2nd European Symposium on Fire Safety Science, Nicosia, Cyprus, 16-18 June 2015.

51. Shearing, P.R.; Finegan, D.P.; Scheel, M.; Robinson, J.B. Investigating lithium-ion battery materials during overcharge-induced thermal runaway: An operando and multi-scale X-ray CT study. Phys. Chem. Chem. Phys. 2016, 18, 30912-30919.

52. Sun, P.; Huang, X.; Bisschop, R.; Niu, H. A Review of Battery Fires in Electric Vehicles. Fire Technol. 2020, 56, 1361-1410. [CrossRef]

53. Lin, X.; Khosravinia, K.; Hu, X.; Li, J.; Lu, W. Lithium Plating Mechanism, Detection, and Mitigation in Lithium-Ion Batteries. Prog. Energy Combust. Sci. 2021, 87, 100953. [CrossRef]

54. Ng, B.; Coman, P.T.; Faegh, E.; Peng, X. Low-Temperature Lithium Plating/Corrosion Hazard in Lithium-Ion Batteries: Electrode Rippling, Variable States of Charge, and Thermal and Nonthermal Runaway. ACS Appl. Energy Mater. 2020, 3, 3653-3664. [CrossRef]

55. Gabbar, H.A.; Othman, A.M.; Abdussami, M.R. Review of Battery Management Systems (BMS) Development and Industrial Standards. Technologies 2021, 9, 28. [CrossRef]

56. National Fire Protection Association. National Electrical Code; National Fire Protection Association: Quincy, MA, USA, 2011.

57. Mitolo, M.; Montazemi, P. Electrical Safety in the Industrial Workplace: An IEC Point of View; IEEE: San Diego, CA, USA, 2014.

58. Zakrzewicz, W.; Sys, E.; Mrowicki, A.; Siczek, K.; Kubiak, P. Safety Issues for Electric and Hybrid Vehicles; IEEE: Kielce, Poland, 2020.

59. Brigade Electronics. Acoustic Vehicle Alerting System (AVAS). 2020. Available online: https://brigade-electronics.com/products/ reversing-and-warning-alarms / quiet-vehicle-sounder/ (accessed on 11 August 2021).

60. Forman Vehicle Services. V-AVAS. 2020. Available online: https://www.formanvehicleservices.com/electronic-systems/v-avas/ (accessed on 11 August 2021). 
61. BSI Group. Standards and Electric Vehicles. 2020. Available online: https://www.bsigroup.com/en-GB/blog/manufacturingblog/standards-and-electric-vehicles / (accessed on 20 June 2021).

62. International Organisation for Standardisation. ISO 26262-1:2018. 2018. Available online: https://www.iso.org/standard/68383. html (accessed on 2 August 2021).

63. National Instruments Corp. What Is the ISO 26262 Functional Safety Standard? 2021. Available online: https:/ /www.ni.com/engb/innovations/white-papers/11/what-is-the-iso-26262-functional-safety-standard-.html (accessed on 2 August 2021).

64. International Organisation for Standardisation. Why ISO 9001? 2021. Available online: https://www.iso.org/iso-9001-qualitymanagement.html (accessed on 2 August 2021).

65. UK Government. Vehicle Approval. 2021. Available online: https://www.gov.uk/vehicle-approval/individual-vehicle-approval (accessed on 15 August 2021).

66. DVSA. Individual Vehicle Approval (IVA) Inspection Manual: Passenger Vehicles (M1); Driver and Vehicle Standards Agency: London, UK, 2020.

67. DVSA. Individual Vehicle Approval (IVA) Inspection Manual: Buses and Coaches (M2 and M3); Driver \& Vehicle Standards Agency: London, UK, 2020.

68. United Nations Economic Commission for Europe Council. Regulation No 100 of the Economic Commission for Europe of the United Nations (UNECE)—Uniform Provisions Concerning the Approval of Vehicles with Regard to Specific Requirements for the Electric Power Train (2015/505); UNECE: Geneva, Switzerland, 2015.

69. UK Government. Vehicles Exempt from Vehicle Tax. 2021. Available online: https://www.gov.uk/vehicle-exempt-from-vehicletax (accessed on 15 August 2021).

70. DVLA. Rates of Vehicle Tax; Driver \& Vehicle Licensing Agency: London, UK, 2021.

71. EDF Energy. Company and Road Tax Benefits on Electric Cars. 2021. Available online: https://www.edfenergy.com/electriccars / tax-road-company (accessed on 21 July 2021).

72. Office for Zero Emission Vehicles. Electric Vehicle Homecharge Scheme: Guidance for Customers. 17 March 2021. Available online: https:/ / www.gov.uk/government/publications/customer-guidance-electric-vehicle-homecharge-scheme/electricvehicle-homecharge-scheme-guidance-for-customers (accessed on 25 June 2021).

73. Office for Zero Emission Vehicles. Vehicles Eligible for the Electric Vehicle Homecharge Scheme. 23 July 2021. Available online: Assets.publishing.service.gov.uk/government/uploads/system/uploads/attachment_data/file/1005589/evhs-eligiblevehicles.csv / preview (accessed on 29 July 2021).

74. Transport for London. Scrappage Schemes. 2021. Available online: https://tfl.gov.uk/modes/driving/scrappage-schemes (accessed on 28 June 2021).

75. Jolly, J. UK Slashes Grants for Electric Car Buyers While Retaining Petrol Vehicle Support; The Guardian: London, UK, 2021.

76. UK Government. Low-Emission Vehicles Eligible for a Plug-in Grant. 2021. Available online: https://www.gov.uk/plug-in-carvan-grants (accessed on 16 August 2021).

77. Horobin, W.; Patel, T. France Maps Out Lower Electric-Car Subsidies Ahead; Bloomberg Green: New York, NY, USA, 2020.

78. Electrive. Germany Doubles EV Subsidies, No More Diesel Support. 2020. Available online: https://www.electrive.com/2020/0 6/04/germany-doubles-ev-subsidies-no-more-diesel-support/ (accessed on 22 July 2021).

79. Groupe Renault. Subsidies in Germany: How Do They Work? 2021. Available online: https:/ / easyelectriclife.groupe.renault com/en/outlook/cities-planning/subsidies-in-germany-how-do-they-work/ (accessed on 22 July 2021).

80. Department for Transport. Bus Service Operators Grant: Guidance for Commercial Transport Operators. 23 September 2019. Available online: https://www.gov.uk/government/publications/bus-service-operators-grant-guidance-for-commercialtransport-operators/bus-service-operators-grant-guidance-for-commercial-transport-operators (accessed on 26 July 2021).

81. UK Parliament. Funding of Bus Services. 22 May 2019. Available online: https://publications.parliament.uk/pa/cm201719/ cmselect/cmtrans/1425/142507.htm (accessed on 26 July 2021).

82. Route One. The Green Recovery and Shaking the BSOG Tree. 28 May 2020. Available online: https://www.route-one.net/ opinion/the-green-recovery-and-shaking-the-bsog-tree/ (accessed on 26 July 2021).

83. Transport Scotland. Bus Services Operators' Grant. 2019. Available online: https://www.transport.gov.scot/public-transport/ buses/bus-services-operators-grant/ (accessed on 26 July 2021).

84. UK Government. Consultation Outcome: Outcome and Resposne to the Ending the Sale of New Petrol, Diesel and Hybrid Cars and Vans. 10 March 2021. Available online: https:/ / www.gov.uk/government/consultations/consulting-on-ending-the-saleof-new-petrol-diesel-and-hybrid-cars-and-vans / outcome/ ending-the-sale-of-new-petrol-diesel-and-hybrid-cars-and-vansgovernment-response (accessed on 5 July 2021).

85. Biswas, W. Life Cycle Environmental Benefits from the Use of Retrofit Electric Vehicles in Western Australia; Australian Life Cycle Assessment Society: Perth, Australia, 2013.

86. Helmers, E.; Dietz, J.; Hartard, S. Electric car life cycle assessment based on real-world mileage and the electric conversion scenario. J. Life Cycle Assess. 2017, 22, 15-30. [CrossRef]

87. Karthik, D.M.; Giriyapur, A.C. Retrofitting of an Engine Powered Vehicle into an Electric Vehicle; IEEE: Tirunelveli, India, 2019.

88. Wilmes, M.; Kraaijeveld, R.; Schrage, M.; Schummers, F. Challenges and Solutions of Converting Conventional Vehicles to Hybrid Electric or Battery Electric Vehicles; Springer Vieweg: Wiesbaden, Germany, 2019. 
89. Volkswagen Vans. ABT e-Transporter Brochure. 8 June 2021. Available online: https:/ /www.volkswagen-vans.co.uk/app/local/ download-brochure.html?model=ABT-e--Transporter-6.1 (accessed on 28 June 2021).

90. Drive Electric. London Congestion Charge. 2020. Available online: https://www.drive-electric.co.uk/london-congestion-charge/ (accessed on 19 July 2021).

91. DEFRA. Clean Air Zones. 7 July 2021. Available online: https:/ /www.gov.uk/guidance/driving-in-a-clean-air-zone (accessed on 19 July 2021).

92. FleetNews. What Are the Proposed UK Clean Air Zones (CAZ)? 2021. Available online: https://www.fleetnews.co.uk/fleet-faq/ what-are-the-proposed-uk-clean-air-zones-caz (accessed on 15 August 2021).

93. UK Government. Drive in a Clean Air Zone. 2021. Available online: https://vehiclecheck.drive-clean-air-zone.service.gov.uk/ vehicle_checkers/enter_details (accessed on 15 August 2021).

94. Transport for London. Ultra Low Emission Zone. 2021. Available online: https://tfl.gov.uk/modes/driving/ultra-low-emissionzone (accessed on 19 July 2021).

95. BBC News. Clean Air Zones: Where Will UK Drivers Pay for Polluting; BBC News: London, UK, 2019.

96. Zemo Partnership. The Clean Vehicle Retrofit Technology Guide; Zemo Partnership: London, UK, 2021.

97. Horiba Mira. HORIBA MIRA Urges Bus Owners and Operators to Consider Retrofitting Amid £50m e-Bus Pledge. 2021. Available online: https: / / www.horiba-mira.com/media-centre/news/2019/10/21/horiba-mira-urges-bus-owners-and-operators-toconsider-retrofitting-amid-50m-e-bus-pledge/ (accessed on 15 August 2021).

98. Route One. Don't Forget Retrofit in the Rush to an Electric Bus Transition. 2021. Available online: https://www.route-one.net/ opinion/dont-forget-retrofit-in-the-rush-to-an-electric-bus-transition/ (accessed on 15 August 2021).

99. Magtec. City Sightseeing Bus EV Conversion: Quick Facts; Magtec: Rotherham, UK, 2021.

100. XE. XE Currency Converter. 2021. Available online: https://www.xe.com/currencyconverter/convert/?Amount=1\&From= EUR\&To=GBP (accessed on 3 November 2021).

101. Nissan. New Nissan Leaf: Prices \& Specifications. 2021. Available online: https://www.nissan.co.uk/vehicles/new-vehicles/ leaf/prices-specifications.html (accessed on 15 August 2021).

102. Peugeot. Peugeot e-208 \& 208: The 5-Door Electric City Car. 2021. Available online: https://www.peugeot.co.uk/models/208. html (accessed on 18 August 2021).

103. Electric Classic Cars. Electric Classic Cars Shop. 2018. Available online: https://www.electricclassiccars.co.uk/shop (accessed on 15 August 2021).

104. Cross, D. Sustainable Driving: The Cost of Converting Your Classic Car to Electric, Fluxposure-The Adrian Flux Blog. 2020. Available online: https:/ / www.adrianflux.co.uk/blog/2020/02/the-cost-of-converting-your-classic-car-to-electric.html (accessed on 15 August 2021).

105. Zero EV. Zero EV-Electric Vehicle Specialists. 2019. Available online: https://zero-ev.co.uk/?v=79cba1185463 (accessed on 15 August 2021).

106. Falcon Electric Limited. Falcon Electric: Making Electric Vehicles Exciting. 2020. Available online: https://falconelectric.co.uk/ (accessed on 15 August 2021).

107. eDub Conversions. eDub Conversions: Classic Car Electric Conversions. 2021. Available online: https://edubconversions.co.uk/ (accessed on 15 August 2021).

108. Electron Garage Ltd. Electron Garage: EV Conversion, Classic Cars to Electric. 2021. Available online: https://www. electrongarage.co.uk/ (accessed on 15 August 2021).

109. Electrogenic Ltd. Electrogenic. 2021. Available online: https:/ /www.electrogenic.co.uk/ (accessed on 15 August 2021).

110. Dron, W. Classic Car Electric Conversion Is on the Rise-We Visit One Specialist to Find Out Why. 2021. Available online: https://www.driving.co.uk/news/features/classic-car-electric-conversion-electrogenic/ (accessed on 24 August 2021).

111. London Electric Cars. London Electric Cars-Convert Your Car to Electric! 2020. Available online: https:/ /www.londonelectriccars. $\mathrm{com} /$ (accessed on 15 August 2021).

112. Everrati. Home-Everrati: Future Proofing Past Masters. 2021. Available online: https://www.everrati.com/ (accessed on 15 August 2021).

113. Lunaz Design. Discovery-Lunaz Design-Classic Electric Cars. 2021. Available online: https://lunaz.design/ (accessed on 15 August 2021).

114. Pollard, T. Putting the range in the classic Range Rover-Lunaz EV conversions. Car Magazine, 7 December 2020.

115. RBW Electric Classic Cars. RBW Classic Electric Sports Cars. 2020. Available online: https://rbwevcars.com/ (accessed on 15 August 2021).

116. Department for Transport. Historic (Classic) Vehicles: MOT Exemption Criteria. 2018. Available online: https://www.gov.uk/ government/publications/historic-classic-vehicles-mot-exemption-criteria/historic-classic-vehicles-mot-exemption-criteria\# substantial-changes-criteria (accessed on 2 August 2021).

117. Energy Saving Trust. Clean Vehicle Retrofit Accreditation Scheme. 2021. Available online: https://energysavingtrust.org.uk/ service/clean-vehicle-retrofit-accreditation-scheme/ (accessed on 5 July 2021).

118. TotalEnergies. What Is SCR Technology? 29 July 2020. Available online: https:// changeforblue.com/en/vehicles-adblue/whatis-scr-technology/ (accessed on 11 August 2021). 
119. Ligang, T.; Yage, G. An investigation on the catalytic characteristic of NOx reduction in SCR systems. J. Taiwan Inst. Chem. Eng. 2019, 99, 53-59.

120. Kaushik, M.K. Acid Rain-A Contemporary World Problem; BBSBEC: Fatehgarh, India, 2006.

121. Fenger, J. Air pollution in the last 50 years-From local to global. Atmos. Environ. 2009, 43, 13-22. [CrossRef]

122. Domingo, J.L. Effects of air pollutants on the transmission and severity of respiratory viral infections. Environ. Res. 2020, 187, 109650. [CrossRef]

123. Drive Lpg. Environmental Benefits. 2021. Available online: https://www.drivelpg.co.uk/about-autogas/environmentalbenefits / (accessed on 21 July 2021).

124. Energy Saving Trust. Low Emission Zone Retrofit Fund. 2021. Available online: https:/ / energysavingtrust.org.uk/grants-andloans/low-emission-zone-retrofit-fund/ (accessed on 9 July 2021).

125. Drive Lpg. Where Can I Find an Approved Installer. 2021. Available online: https:/ /www.drivelpg.co.uk/approved-installers/ find-an-approved-installer/ (accessed on 27 June 2021).

126. UKLPG. Autogas Approved Installers Scheme. June 2014. Available online: https://www.liquidgasuk.org/uploads/DOC5A8C2 E11780A0.pdf (accessed on 20 June 2021).

127. UK Government. Change Vehicle Details on a V5C Registration Certificate (Log Book). 2021. Available online: https://www.gov. uk/change-vehicle-details-registration-certificate (accessed on 21 June 2021).

128. UK Government. Change Your Vehicle's Tax Class. 2021. Available online: https://www.gov.uk/change-vehicle-tax-class/taxnot-due-to-run-out (accessed on 26 June 2021).

129. UK Government. Vehicle Registration: Radically Altered Vehicles. 2021. Available online: https://www.gov.uk/vehicleregistration/radically-altered-vehicles (accessed on 26 June 2021).

130. DVSA. Tell DVSA about an Alteration to a Public Service Vehicle (PSV). 2021. Available online: https://www.gov.uk/ government/publications/notification-of-an-alteration-to-a-public-service-vehicle-vtp-5 (accessed on 15 August 2021).

131. DVSA. Notification of an alteration to a PSV. 29 January 2021. Available online: https://assets.publishing.service.gov.uk/ government/uploads/system/uploads/attachment_data/file/957230/notification-alteration-to-public-service-vehicle.pdf (accessed on 15 August 2021).

132. DVSA. PSV Notifiable Alterations: STANDARDS of Compliance for Re-Approval. 2013. Available online: https: / / www.gov.uk/government/publications / guide-to-notifiable-alterations-to-a-psv / psv-notifiable-alterations-standardsof-compliance-for-re-approval (accessed on 15 August 2021).

133. DVLA. Hybrid, Electric and Hydrogen Fuel Cell Systems: Guidance for MOT Testers. 2021. Available online: www.gov. uk/government/publications / alternative-fuel-vehicles-guidance-for-mot-testers / hybrid-electric-and-hydrogen-fuel-cellsystems-guidance-for-mot-testers (accessed on 2 August 2021).

134. UK Government. Check If a Vehicle Is Taxed and Has an MOT. 2021. Available online: https://vehicleenquiry.service.gov.uk/ (accessed on 16 August 2021). 